\title{
Excessive Continuation and Dynamic Agency Costs of Debt.
}

\author{
Jean-Paul Décamps * and Antoine Faure-Grimaud ${ }^{\dagger}$
}

\author{
March 7, 2000
}

*GREMAQ, University of Toulouse 1, 21 Allée de Brienne, Manufacture des Tabacs, 31000 Toulouse, France. Fax: +33 5612255 63, email: decamps@cict.fr

${ }^{\dagger}$ London School of Economics \& FMG, Houghton Street, London WC2A 2AE, UK. Fax: +44 171 955 6887, and CEPR. email:a.faure-grimaud@lse.ac.uk. This paper partly originates from an other work entitled "Pricing the Gamble for Resurrection and the Consequences of Renegotiation and Debt Design" and has greatly benefitted from the comments and suggestions made by the audiences of the seminars where this first paper has been presented. In particular, we thank the participants at the conference "Valuation of defaultable bonds" (March 1997) organised by the Financial Markets Group and especially our discussant R. Anderson, the participants at the summer seminar in finance at the Haas School of Business, at the ESEM 97, at the University of Cambridge, at the University of Toulouse, at the London Business School, at the Finance symposium in Gersenzee (1998), at the AFFI (1998), at the FIQUAM workshop (1998) in Aspet, at the TMR Workshop (1998) in Firenze and at CIRANO (Montreal 1999). Part of this research was conducted when the first author was visiting the Haas School at the University of Berkeley and the Financial Markets Group at the LSE, he thanks these institutions for their hospitality. All remaining errors are ours. 


\begin{abstract}
This paper analyses the incentives of the equityholders of a leveraged company to shut it down in a continuous time, stochastic environment. Keeping the firm as an ongoing concern has an option value but equity and debt holders value it differently. Equityholders' decisions exhibit excessive continuation and reduce firm's value. Using a compound exchange option approach, we characterise the resulting agency costs of debt, derive the "price" of these costs and analyse their dynamics. We also show how agency costs can be reduced by the design of debt and the possibility of renegotiation.
\end{abstract}

Jel Classification: G30, G13, L10. 


\section{Introduction}

This paper aims at integrating the study of dynamic agency costs in an option pricing model. The objectives are, on the one hand to derive new theoretical insights on the dynamics of agency relationships -most of the corporate finance literature concerned with incentive problems remains static- and, on the other hand, to characterise the consequences of these conflicts on the pricing of financial securities -most of the pricing literature supposes the Modigliani-Miller dichotomy between real and financial decisions.

We limit ourselves to a particular sort of agency conflict: the reluctance of equityholders to shut down the activities of a leveraged company. The shareholders of an indebted firm may keep the company as an ongoing concern in the hope that its situation may improve, even though shutting down the firm is more valuable in expected terms. The possibility of excessive continuation stems from the conflict of interest existing between equityholders and debtholders: limited liability shifts the cost of losses to the latter and allows equityholders to benefit from significant upturns. Our focus is motivated by empirical considerations ${ }^{1}$, by the important static corporate finance literature devoted to it (starting with Jensen and Meckling (1976)) and also by the extent to which the problem naturally fits an option framework. In fact, our work can also be viewed as an attempt to blend a model of financial option with a real option problem.

It is worth emphasizing that we do not attempt at deriving an optimal capital structure: we only focus on a cost of debt. One could introduce other elements justifying that debt financing may be desirable in the first place but our objective is to derive a lower bound for any possible expected benefit of debt to make this form of financing desirable.

Our model is designed to be the simplest one capturing the possibility of excessive continuation, in a continuous time environment. The analysis requires the use of a compound exchange option methodology. The results are obtained by extending the variational ap-

\footnotetext{
${ }^{1}$ The relevance of excessive continuation problems, which can be viewed as a consequence of the asset substitution effect and can sometimes take the more radical form of a "gamble for resurrection" when the firm is in financial distress, is supported by many stylised facts (see for instance Grinblatt and Titman (1998)). However, to the best of our knowledge there is no econometric study specifically devoted to this problem.
} 
proach to option pricing developed by Décamps and Rochet (1997) to this setting.

With respect to our "pricing" objective, we characterise the agency costs associated with any possible capital structures. We derive a closed-form formula for the magnitude of these costs in the case of straight debt. We also perform some comparative static exercises and we show the value of the firm monotonically decreases with total leverage. Regarding the insights on the dynamics of agency costs, we derive a condition ensuring that the closer the firm gets to the debt maturity, the higher the agency costs. These costs can nonetheless be reduced by a dynamic renegotiation process and we characterise the optimal sequence of renegotiation offers in an ideal world where renegotiation between equity and debt holders is frictionless. We also investigate the optimal allocation of coupons. Keeping total leverage constant, the allocation of coupons modifies the value of the firm because these coupons affect the "risk of a gamble". We show that issuing coupon debt dominates zero coupon debt, keeping total leverage constant.

The relation to the literature is discussed once the model is introduced which is the object of section 2. Section 3 is devoted to the case of zero coupon debt financing while section 4 shows how the agency costs of debt financing can be reduced by renegotiation and coupon design. Finally, a short section concludes.

\section{The General Framework}

\subsection{A Simple Model of the Firm.}

We start by presenting a very stylised model of the firm. A firm is characterised by the existence at an initial date (hereafter date 0) of both an entrepreneur and a project. This project necessitates some initial investment $-S_{0}$ denotes its cost-, and has a finite maturity T. Namely, we will assume that if completed, the project will generate some stochastic cash flows at a date $T . V(T)$ denotes the value of these cash flows at date $T$. In a risk neutral world, $V(t)$ will then represent the discounted expectation of these final returns, at date $t$. For simplifying the terminology, we will refer to $V(t)$ as the current value of the firm's assets. One can interpreted it as the value of these assets when the entrepreneur 
uses them to produce some goods and services which are then sold in the product market.

The managers of the firm have the option to shut it down before final completion of the project. This decision is irreversible: once the company is shut down, its activity cannot be restarted. If so, the different claimholders have to share the residual value (we will also call it the "scrap value") of the physical assets. If they decide to abandon the productive activity of the firm at date $t_{i}$, they receive an amount of cash $S\left(t_{i}\right)$ at that date. This residual value may differ from the current value (which again is the expected value of the cash flows at the terminal date) for several reasons. For instance, $S$ represents the resale value of the assets in the second-hand market while $V$ is the expected profit that these assets, in conjunction with the human capital of the managers/equityholders, can generate. The presence of some specific human capital may explain why the resale price of the physical assets is less than $V$. The difference can also come from a reputation effect (negative or positive) embodied in the current value of a company but not in the value of its physical assets. This may include as well a factor reflecting the competitive position of the company. More generally, the difference $V-S$ will represent any sort of intangible asset $^{2}$ likely to affect the profitability of the company. To put it differently, assuming there were a market for these intangible assets, their price plus the cost of acquiring the physical assets will be equal, in equilibrium, to the current value of the firm $V$. Whenever these intangible assets have a positive value, $V$ will be higher than $S$ but we may as well consider the case where this difference is negative (firms with a bad reputation for instance, or in a poor competitive position). In general, the empirical fact that Tobin's Qs tend to differ from one provides some support to our assumption that $V-S \neq 0$.

Given our single project firm, the value of the company will be determined by the expected value of the future cash-flows -should the project be completed-, the residual value of the assets -if not- and the possibility to shut down the firm. Consequently, characterising the exercise policy of such a real option will be central to our analysis.

It is important to emphasis that this shut down decision is not independent of the

\footnotetext{
${ }^{2}$ This interpretation also supports our assumption that a shut down is irreversible: even if the physical assets can be bought in the market, reputation or market position are idiosyncratic to firms. One cannot easily buy these characteristics which needs to be developed over time.
} 
firm's capital structure. Our focus is on the (dynamic) agency conflicts that may arise between equityholders and debtholders. Indeed, the parties entitled to the control rights will exercise these rights in a way which maximises the value of their income rights. In our model, the shut down decision will not be mechanically determined by a bankruptcy rule. Bankruptcy may be declared when a debt repayment cannot be met and default can trigger a change of control: debtholders will now be entitled to exercise the shut down option but, a priori, they may be willing to continue the firm's activity if such a strategy increases their payoffs ${ }^{3}$. It is also important to distinguish this decision from a pure liquidation process. In both cases, the activity is stopped and the firm leaves the output market. But the stopping decision refers to the decision taken by the agents in control of the firm (whoever they are), potentially independently of any state of default. For instance, an unlevered firm cannot be liquidated even though its activity will be stopped when such a strategy maximises the wealth of its equityholders.

Before characterising the different (endogenous) exercise policies of this real option, we need to specify the stochastic structure of our model. We consider a continuous time economy where time $t$ belongs to a bounded interval $[0, T]$. Capital markets are frictionless and free of informational asymetries. The agents are risk neutral ${ }^{4}$ and can borrow and lend freely at a constant riskless interest rate $r$. Uncertainty is defined by a probability space $(\Omega, \mathcal{F}, Q)$. The flow of information accruing to the agents is represented by the continuous filtration $\left(\mathcal{F}_{t}\right)_{t \in[0, T]}$ associated to a two dimensional $Q$ Brownian motion $\left(W_{1}, W_{2}\right)$. $\mathcal{F}_{0}$ is trivial and $\mathcal{F}_{T}$ is equal to $\mathcal{F}$.

The productive value $V$ and the scrap value $S$ of the firm's assets are assumed to obey the lognormal diffusion processes:

$$
\left\{\begin{array}{l}
\frac{d V}{V}=r d t+\sigma_{V} d W_{1}(t) \\
V_{0}>0
\end{array}\right.
$$

\footnotetext{
${ }^{3}$ Continuation under debtholders' control can refer to a form of reorganisation made possible by the bankruptcy code, like for instance as it is the case in the US with Chapters 7 and 11.

${ }^{4}$ The risk neutrality assumption represents little loss of generality. If agents were risk averse, the analysis could be conducted using risk neutral probabilities rather than actual probabilities (see Harrison and Kreps (1979)).
} 


$$
\left\{\begin{array}{l}
\frac{d S}{S}=\delta d t+\sigma_{S} d W_{2}(t) \\
S_{0}>0
\end{array}\right.
$$

where $\delta$ is a real constant, the volatilities $\sigma_{V}$ and $\sigma_{S}$ are positive constants. $V_{0}$ is the initial productive value of the firm's assets, $S_{0}$ is the initial scrap value of the firm's assets (which is also the investment cost). The two standard Brownian motions $W_{1}$ and $W_{2}$ are assumed to be correlated. Typically, one may suspect a positive correlation, reflecting that the residual value of an asset is likely to be higher when the productive value is itself higher.

We suppose the current value of the firm's assets $V$ is a traded asset ${ }^{5}$. Under the risk neutrality assumption the instantaneous rate in equation (1) is thus equal to the riskless interest rate $r$. In contrast, we consider that the scrap value of the physical asset is not a traded asset, (as a consequence, the instantaneous rate of return $\delta$ in equation (2) can be different from $r$ ). Our justification is that, as long as the firm is in activity, this residual value does not correspond to any real process. It is only once the shut down decision has been taken that an amount of cash $S$ is available to claimholders. The dynamics of this cash-flow are given by equation (2).

In order to use the option pricing methodology, we classically assume that stochastic changes in $S$ are spanned with existing assets. In other words, markets are sufficiently complete and it is possible to find an asset or to construct a dynamic portfolio of assets the price of which is perfectly correlated with $S$.

Finally, we assume that the scrapping decision can be taken at a finite number of dates, $0<t_{1}<t_{2}<\ldots<t_{n}<T^{6}$. This modelling can be motivated by the remark that the shut down decision can only be taken during a meeting of the board of directors or necessitates some form of communication between leading shareholders and management. These communications can only happen at fixed time intervals. We nevertheless also investigate in the sequel the case where the shut down decision is made in continuous

\footnotetext{
${ }^{5}$ The results we derive thereafter can also be obtained without making this standard assumption. Ericsson and Reneby (1997) proposes a detailed discussion of the different assumptions about the trading of assets and firm's values.

${ }^{6}$ The case $t_{n}=T$ will also be discussed. $t_{n}<T$ introduces a second element of irreversibility in the continuation decision: after date $t_{n}$, the shut down option is definitely lost.
} 
time.

\subsection{Relation with the Literature.}

Since the pioneering work of Mello and Parsons (1992), some recent articles have incorporated agency problems into an option pricing framework.

Ericsson (1997) and Leland (1998) investigate the asset substitution problem where a firm can modify the volatility of its value. ${ }^{7}$ Considering a leveraged company, these authors compare the choice of two possible levels for the volatility parameter of the firm and show that the one which is optimal ex ante is usually not the one chosen after debt has been issued. Two theoretical problems limit their analysis. First, one should explain why the volatility parameter choice is restricted to a particular subset of values. Indeed, without such a restriction, equityholders will benefit from infinite volatility choices as their claim is a convex function of the underlying asset ${ }^{8}$. Second, the welfare efficiency of the policy chosen should be assessed against a benchmark case. The standard benchmark is typically defined by the policy maximising the value of an unlevered firm. In these articles, the value of an unlevered firm at the initial date is independent of the volatility choice: from a normative point of view, one cannot say that a particular volatility level is more efficient than another one.

Mella-Barral and Perraudin (1997) characterise the consequences of the capital structure on an abandonment decision. They exhibit an underinvestment (too much abandonment) result. This comes from the fact that equityholders have to inject new cash in the firm to keep it as an ongoing concern. To some extent, their continuation decision can be reinterpreted as an investment decision. Similarly, Mauer and Ott (1998) consider the investment in a growth option by equityholders of a leveraged company and also exhibit an underinvestment result for exactly the same reason. These papers thus offer a continuous time version of the sort of problems first examined in Myers (1977): the

\footnotetext{
${ }^{7}$ Leland (1994) and Leland and Toft (1996) also touch on asset substitution, but are mainly concerned with the optimal capital structure which balances the tax benefits and the bankruptcy costs coming with debt.

${ }^{8}$ This is still true for a large range of parameter values even if bankruptcy costs are introduced as in Leland (1998).
} 
injection of new cash by equityholders has a positive externality on debtholders' claims and the continuation (or expansion) decision is less than optimal because equityholders do not internalise this effect. Anderson and Sundaresan (1996) and Mella-Barral (1999) more specifically study the renegotiation game which may result between equityholders and debtholders and also allow for the possibility of strategic default.

We study here the complementary case where continuing the current activity does not require new funds but, along the lines of the literature pioneered by Jensen and Meckling (1976), where risk taking behaviour is the crucial ingredient of the agency conflict. Keeping the firm alive is a risky strategy while stopping it yields, at that date, a certain amount of cash to the different claimholders. From an empirical point of view, excessive continuation problems are well documented even in their extreme form of the "gamble for resurrection", from the evidence concerning the banking industry ${ }^{9}$ to some high profile bankruptcy $\operatorname{cases}^{10}$. Parrino and Weisbach (1999) also provide some simulations showing that the gamble for resurrection is likely to be much more of a problem in realistic industry conditions. The static corporate finance literature has also extensively considered excessive continuation problems, either motivated by risk-loving attitudes or by the existence of private benefits of control ${ }^{11}$.

Our paper is also related to the real option literature ${ }^{12}$ as the possibility to scrap down the firm is a real option whose value has been characterised for instance by McDonald and Siegel (1985) or Dixit and Pyndick (1994) in the context of an all-equity firm (financial decisions are not considered). In our setting, with discrete scrapping dates, compound exchange options play a crucial role. MacDonald and Siegel (1985) derive the analogue of the Margrabe (1978)'s formula for exchange options in the case of non traded assets. Using

\footnotetext{
${ }^{9}$ One should of course take into account the role played by the deposit insurance systems in this case. Notice however that the consequences of such a system with respect to our problem are essentially to shift the cost of excessive risk taking from depositors to the insurance system. One may argue that the insurance system exacerbates the gambling problem as rational depositors would anticipate banks' behaviour and charge a risk premium. Nonetheless, removing the deposit insurance system would not eliminate the gambling problem: banks would like to commit ex ante to adopt safer strategies but $e x$ post (once they have obtained the funds), their incentives to take on risks are exactly the same as with deposit insurance.

${ }^{10}$ See Grinblatt and Titman (1998) for some detailed examples.

${ }^{11}$ see the survey by Harris and Raviv (1991).

${ }^{12}$ For a survey of this literature, see for instance Sick (1995).
} 
standard arbitrage derivations, Carr (1988) obtains the price of a compound exchange option and discusses the application of his formula to investment decision problem. Using the variational approach developed by Décamps and Rochet (1997), we revisit Carr's (1988) formula: The compound exchange option price is now obtained as the value of an optimization problem. This allows us in particular to propose in section 3 a generic formula for the magnitude of the agency costs. This formula is written as the difference between two identical compound exchange options with different exercise policies.

Finally, to the best of our knowledge, our paper also differs from the rest of the literature by not assuming some form of stationarity. Most of the aforementioned papers in continuous time consider perpetual coupon debt ${ }^{13}$. By construction, these papers cannot address the questions of the dynamics of agency costs, of the allocation of coupons over time and of the evolution of renegotiation offers as the firm gets closer to the maturity. Although agency problems are by now well understood in various static environments, not much work has been done for analysing their dynamics. Our work aims to be a step in this direction and we try to develop a dynamic model as close as possible to the existing analysis of, for instance, Dewatripont and Tirole (1994) or Hart and Moore (1989, 1994, 1996). A dynamic extension of these models requires a non stationary environment. The paper closest to ours from this literature is Hart and Moore (1994). Our paper is different and complementary to theirs. In a deterministic environment, they focus on the bargaining game between an entrepreneur who has borrowed some funds and an external creditor, given that the entrepreneur can strategically run away from the company. The value of the company is supposed to differ whether the entrepreneur or the creditor is managing it. Hart and Moore (1994) are concerned with the optimal allocation of residual rights of control and characterize how debt can implement the optimal mechanism. We simplify, and most of the time ignore, the renegotiation game and the optimal allocation of control by assuming that there is no intermediate cash flows if the firm is kept as an ongoing concern (however, we will characterize how coupon debt can transfer decision rights in the debtholders hands and the resulting consequences on the continuation decisions). We are essentially concerned with how the split of income rights induced by debt in a dynamic

\footnotetext{
${ }^{13}$ A noticeable exception is Leland and Toft (1996) which considers a finite maturity debt but this debt is rolled over continously.
} 
and stochastic environment leads equity and debt holders to value differently the option of not liquidating the firm. The agency conflict comes from this difference and is not assumed to exist in the first place because of some intrinsic differences between what the entrepreneur and the creditor can do. Although we do not derive the optimal financial contract and take debt as given, our framework also allows us to consider some problems related to its design, to the allocation of coupons over time and to the possibility of renegotiation at different dates. Even in the absence of stationarity, we will obtain quasi closed form solutions for the firm's value and the agency costs of debt in the various cases.

\subsection{Preliminary Analysis: a Compound Exchange Approach}

This paragraph presents some technical results which will prove useful in the sequel. They extend the variational approach developed by Décamps and Rochet (1997) to the context of compound exchange options.

Let $X(t)$ denote the price at date $t$ of a traded asset ${ }^{14}$. Let $C_{n}(X(t), S(t), t)$ denote the price at date $t,\left(t<t_{1}<\ldots<t_{n}\right)$, of the compound exchange option which gives the right to exchange at date $t_{n}$ the scrap value of the firm's assets $S\left(t_{n}\right)$ for $X\left(t_{n}\right)$ and to exchange at dates $t_{n-i}(1 \leq i \leq n-1), \tilde{S}\left(t_{n-i}\right)=\left(1-e^{-(r-\delta)\left(t_{n-i+1}-t_{n-i}\right)}\right) S\left(t_{n-i}\right)$ for $C_{i}\left(X\left(t_{n-i}\right), S\left(t_{n-i}\right), t_{n-i}\right)$ where $C_{1}\left(X\left(t_{n-1}\right), S\left(t_{n-1}\right), t_{n-1}\right)$ denotes the value at date $t_{n-1}$ of the option to exchange at date $t_{n} S\left(t_{n}\right)$ for $X\left(t_{n}\right)$. The subscript $i$ under $C$ refers to the fact, that, at date $t_{n-i}$, there are $i$ future exercise dates pending. Let $\Phi_{n}\left(X(t), S(t), t ; \mathcal{A}_{1}, \mathcal{A}_{2}, \cdots, \mathcal{A}_{n}\right)$ denote the price at date $t$ for an arbitrary exercise policy $\mathcal{A}_{1}, \mathcal{A}_{2}, \cdots, \mathcal{A}_{n}$ of the compound option described previously. Under these notations the following holds.

\footnotetext{
${ }^{14} \mathrm{As}$ it will be clear, the traded assets $X$ which naturally appear in our analysis are (i) the traded asset associated to the productive value of the firm (whose price at $t$ is $V(t)$ ), (ii) the portfolio composed of the traded asset associated to the productive value of the firm and of the put option written on this asset with exercise price the face value of the debt $M$ and exercise date the expiring date of the debt $T$ (whose price at date $t$ is $V(t)+P(V(t), M, T-t)$ ). Hence, in the sequel $X(t)$ will be either $V(t)$ ot $V(t)+P(V(t), M, T-t)$
} 


\section{Lemma 1}

$$
\begin{aligned}
\Phi_{n}\left(X(t), S(t), t ; \mathcal{A}_{1}, \cdots, \mathcal{A}_{n}\right) & =\mathbb{E}_{t}\left[e^{-r\left(t_{n}-t\right)}\left(X\left(t_{n}\right)-S\left(t_{n}\right)\right) \mathbb{I}_{\mathcal{A}_{1} \cap \cdots \cap \mathcal{A}_{n}}\right] \\
& -\sum_{i=1}^{n-1} \mathbb{E}_{t}\left[e^{-r\left(t_{i}-t\right)} \tilde{S}\left(t_{i}\right) \mathbb{I}_{\mathcal{A}_{1} \cap \cdots \cap \mathcal{A}_{i}}\right] .
\end{aligned}
$$

Proof: By induction on $n$. For $n=1$ the formula is tautological. Suppose it is true for $n-1$, for $t<t_{1}$ we have

$$
\begin{aligned}
& \Phi_{n} \quad\left(X(t), S(t), t ; \mathcal{A}_{1}, \cdots, \mathcal{A}_{n}\right)=\mathbb{E}_{t}\left[e^{-r\left(t_{1}-t\right)}\left(\Phi_{n-1}\left(X\left(t_{1}\right), S\left(t_{1}\right), t_{1}\right)-\tilde{S}\left(t_{1}\right)\right) \mathbb{I}_{\mathcal{A}_{1}}\right] \\
& =\mathbb{E}_{t}\left[e^{-r\left(t_{1}-t\right)}\left\{\mathbb{E}_{t_{1}}\left[e^{-r\left(t_{n}-t_{1}\right)}\left(X\left(t_{n}\right)-S\left(t_{n}\right)\right) \mathbb{I}_{\mathcal{A}_{2} \cap \cdots \cap \mathcal{A}_{n}}-\sum_{i=2}^{n-1} e^{-r\left(t_{i}-t_{1}\right)} \tilde{S}\left(t_{i}\right) \mathbb{I}_{\mathcal{A}_{2} \cap \cdots \cap \mathcal{A}_{n}}\right] \mathbb{I}_{\mathcal{A}_{1}}\right\}\right] \\
& -\mathbb{E}_{t}\left[e^{-r\left(t_{1}-t\right)} \tilde{S}\left(t_{1}\right) \mathbb{I}_{\mathcal{A}_{1}}\right] \\
& =\mathbb{E}_{t}\left[e^{-r\left(t_{n}-t\right)}\left(X\left(t_{n}\right)-S\left(t_{n}\right)\right) \mathbb{I}_{\mathcal{A}_{1} \cap \cdots \cap \mathcal{A}_{n}}\right]-\sum_{i=1}^{n-1} \mathbb{E}_{t}\left[{ }^{-r\left(t_{i}-t\right)} \tilde{S}\left(t_{i}\right) \mathbb{I}_{\mathcal{A}_{1} \cap \cdots \cap \mathcal{A}_{i}}\right]
\end{aligned}
$$

\section{Lemma 2}

$$
C_{n}(X(t), S(t), t)=\max _{\substack{\mathcal{A}_{1} \in \mathcal{F}_{t_{1}} \\ \vdots \\ \mathcal{A}_{n} \in \mathcal{F}_{t_{n}}}} \Phi\left(X(t), S(t), t ; \mathcal{A}_{1}, \mathcal{A}_{2}, \cdots, \mathcal{A}_{n}\right)
$$

Proof: By induction on $n$. For $n=1$, consider $0 \leq t \leq t_{1}$, we have

$$
\begin{aligned}
C_{1}(X(t), S(t), t) & =\mathbb{E}_{t}\left[e^{-r\left(t_{1}-t\right)}\left(X\left(t_{1}\right)-S\left(t_{1}\right)\right)^{+}\right] \\
& =\max _{\mathcal{A}_{1} \in \mathcal{F}_{t_{1}}} \mathbb{E}_{t}\left[e^{-r\left(t_{1}-t\right)}\left(X\left(t_{1}\right)-S\left(t_{1}\right)\right) \mathbb{I}_{\mathcal{A}_{1}}\right] \\
& =\max _{\mathcal{A}_{1} \in \mathcal{F}_{t_{1}}} \Phi_{1}(X(t), S(t), t) .
\end{aligned}
$$


Suppose now the property true for $n-1$ then

$$
\begin{aligned}
& C_{n}(X(t), S(t), t)=\mathbb{E}_{t}\left[e^{-r\left(t_{1}-t\right)}\left(C_{n-1}\left(X\left(t_{1}\right), S\left(t_{1}\right), t_{1}\right)-\tilde{S}\left(t_{1}\right)\right)^{+}\right] \\
& =\max _{\mathcal{A}_{1} \in \mathcal{F}_{t_{1}}} \mathbb{E}_{t}\left[e^{-r\left(t_{1}-t\right)}\left(C_{n-1}\left(X\left(t_{1}\right), S\left(t_{1}\right), t_{1}\right)-\tilde{S}\left(t_{1}\right)\right) \mathbb{I}_{\mathcal{A}_{1}}\right] \\
& =\max _{\mathcal{A}_{1} \in \mathcal{F}_{t_{1}}} \mathbb{E}_{t}\left[e^{-r\left(t_{1}-t\right)}\left(\max _{\mathcal{A}_{2} \in \mathcal{F}_{t_{2}}} \Phi_{n-1}\left(X\left(t_{1}\right), S\left(t_{1}\right), t_{1} ; \mathcal{A}_{2}, \cdots, \mathcal{A}_{n}\right)-\tilde{S}\left(t_{1}\right)\right) \mathbb{I}_{\mathcal{A}_{1}}\right] \\
& \begin{array}{c}
\vdots \\
\mathcal{A}_{n} \in \mathcal{F}_{t_{n}}
\end{array} \\
& =\max _{\substack{\mathcal{A}_{1} \in \mathcal{F}_{t_{1}} \\
\mathcal{A}_{2} \in \mathcal{F}_{t_{2}}}} \mathbb{E}_{t}\left[e^{-r\left(t_{1}-t\right)}\left(\Phi_{n-1}\left(X\left(t_{1}\right), S\left(t_{1}\right), t_{1} ; \mathcal{A}_{2}, \cdots, \mathcal{A}_{n}\right)-\tilde{S}\left(t_{1}\right)\right) \mathbb{I}_{\mathcal{A}_{1}}\right] \\
& \vdots \\
& \mathcal{A}_{n} \in \mathcal{F}_{t_{n}} \\
& =\max _{\mathcal{A}_{1} \in \mathcal{F}_{t_{1}}} \Phi_{n}\left(X(t), S(t), t ; \mathcal{A}_{1}, \cdots, \mathcal{A}_{n}\right) . \\
& \begin{array}{c}
\vdots \\
\mathcal{A}_{n} \in \mathcal{F}_{t_{n}}
\end{array}
\end{aligned}
$$

Remark that the optimal exercise policies at date $t_{n}, t_{n-1}, \cdots, t_{1}$ are defined by the sets

$$
\left\{X\left(t_{n}\right) \geq S\left(t_{n}\right)\right\} \quad \text { and for all } \quad 1 \leq i \leq n-1 \quad\left\{C_{i}\left(X\left(t_{n-i}\right), S\left(t_{n-i}\right), t_{n-i}\right) \geq \tilde{S}\left(t_{n-i}\right)\right\} .
$$

\section{Lemma 3}

$$
\left.\forall 1 \leq i \leq n-1 \quad C_{i}\left(X\left(t_{n-i}\right), S\left(t_{n-i}\right), t_{n-i}\right)\right) \geq X\left(t_{n-i}\right)-e^{-(r-\delta)\left(t_{n-i+1}-t_{n-i}\right)} S\left(t_{n-i}\right) .
$$

\section{Proof:}

Consider $\mathcal{A}_{1}=\mathcal{A}_{2}=\cdots=\mathcal{A}_{n}=\Omega$ and apply Lemma 1 and Lemma 2 .

\section{Capital Structure and Exercise Policies of a Mul- tidate Scrapping Option.}

We make the assumption throughout the analysis that there is no conflict of interest between the managers of the company and itsequityholders. Consequently, managers always choose the policy maximising the value of equuityholders' claims. As a proper benchmark case, we start by characterising the optimal scrapping policy of an unlevered company. We will then move to the case of a levered company. 


\subsection{The first best rule}

Let us denote by $v_{n}\left(V(t), S(t), t ; \mathcal{A}_{1}, \mathcal{A}_{2}, \cdots, \mathcal{A}_{n}\right)$ the value at date $t<t_{1}$ of the firm if the equityholders choose at dates $t_{1}<\cdots<t_{n}$, the continuation policy $\mathcal{A}_{1}, \mathcal{A}_{2}, \cdots, \mathcal{A}_{n}$. The subscript $n$ under $v$ refers to the fact, that, at date $t$, there are $n$ operating decisions to be taken by equityholders. Using the previous lemmata, we prove:

Proposition 1 The value at date $0, v^{*}(0)$, of the all equity benchmark firm is given by the relation

$$
\begin{aligned}
& v^{*}(0)= \max _{\mathcal{A}_{1} \in \mathcal{F}_{t_{1}}} v_{n}\left(V(0), S(0), 0 ; \mathcal{A}_{1}, \mathcal{A}_{2}, \cdots, \mathcal{A}_{n}\right) \\
& \vdots \\
& \mathcal{A}_{n} \in \mathcal{F}_{t_{n}} \\
&= S_{0} e^{-(r-\delta) t_{1}}+\max _{\mathcal{A}_{1} \in \mathcal{F}_{t_{1}}} \Phi_{n}\left(V(0), S(0), 0 ; \mathcal{A}_{1}, \cdots, \mathcal{A}_{n}\right) \\
& \vdots \\
& \substack{\mathcal{A}_{n} \in \mathcal{F}_{t_{n}} \\
=} \\
& S_{0} e^{-(r-\delta) t_{1}}+C_{n}(V(0), S(0), 0) .
\end{aligned}
$$

The optimal continuation policy is defined by the relations:

$$
\begin{aligned}
\mathcal{A}_{n}^{*}=\left\{V\left(t_{n}\right) \geq S\left(t_{n}\right)\right\} & \text { and } \\
\qquad & \left.i, 1 \leq i \leq n-i, \mathcal{A}_{n-i}^{*}=\left\{C_{i}\left(V\left(t_{n-i}\right), S\left(t_{n-i}\right), t_{n-i}\right)\right) \geq \tilde{S}\left(t_{n-i}\right)\right\} .
\end{aligned}
$$

Proof: see appendix.

The policy maximising the value of the firm can easily be understood when adopting a backward reasoning. At the last possible scrapping date $t_{n}$, the optimal decision is clearly to scrap the company if and only if $S\left(t_{n}\right) \geq V\left(t_{n}\right)$. However, this simple comparison is only optimal at the last date. For any date $t_{n-i}$, deciding to stop whenever $S\left(t_{n-i}\right)$ exceeds $V\left(t_{n-i}\right)$ is suboptimal as this rule ignores the option value of continuation. To illustrate this point, consider the decision to be taken at date $t_{n-1}$. Two effects govern the scrapping decision at that date. To disentangle these effects, consider the hypothetical scenario where the equityholders are sure that a shut down decision will be taken at date $t_{n}$, should this date be reached. If instead closure occurs at date $t_{n-1}$, equityholders obtain $S\left(t_{n-1}\right)$ that they compare (in this scenario) with the discounted expected value of $S\left(t_{n}\right)$, i.e. $S\left(t_{n-1}\right) e^{-(r-\delta)\left(t_{n}-t_{n-1}\right)}$. Conditionally on scrapping tomorrow, equityholders should scrap the firm immediately if $S\left(t_{n-1}\right) \geq S\left(t_{n-1}\right) e^{-(r-\delta)\left(t_{n}-t_{n-1}\right)}$. Therefore, $\tilde{S}\left(t_{n-1}\right)$ 
represents the net gain of scrapping the firm now where net means in comparison with the payoff obtained by scrapping the firm at the next possible date. Notice that whenever $r \leq \delta$ this net effect is negative and scrapping should not occur until possibly the last scrapping date $t_{n}$. There is a second effect due to the fact that the firm may not be scrapped at the next date: equityholders could choose to get $V\left(t_{n}\right)$ instead of $S\left(t_{n}\right)$. Given that $C_{1}\left(V\left(t_{n-1}\right), S\left(t_{n-1}\right), t_{n-1}\right)$ denotes the value at date $t_{n-1}$ of the option to exchange at date $t_{n}, S\left(t_{n}\right)$ for $V\left(t_{n}\right)$, equityholders of an unlevered firm should definitely decide to continue at date $t_{n-1}$ if $C_{1}\left(V\left(t_{n-1}\right), S\left(t_{n-1}\right), t_{n-1}\right) \geq \tilde{S}\left(t_{n-1}\right)$. To summarize, keeping the firm alive gives a) the possibility to scrap it latter as opposed to now and b) the (exchange) option to keep it alive latter as opposed to closing it latter.

The same two effects can be distinguished when moving to date $t_{n-2}$. The second effect is modified though, as continuing gives the option to exchange $S\left(t_{n-1}\right)$ for $C_{1}\left(V\left(t_{n-1}\right), S\left(t_{n-1}\right), t_{n-1}\right)$ at the next date, that is to say at $t_{n-1}$. The value of such an option is $C_{2}\left(V\left(t_{n-2}\right), S\left(t_{n-2}\right), t_{n-2}\right)$ and our formula obtains. Similar arguments apply for dates $t_{n-i}$.

This proposition allows us to derive a simple characterisation of the agency costs associated with any possible continuation policy.

Corollary 1 Assume that the choice of the equityholders for a given financial structure is characterized by the continuation policy $\mathcal{A}_{1}, \cdots, \mathcal{A}_{n} .\left(\mathcal{A}_{i} \in \mathcal{F}_{t_{i}}\right)$. Then, such a financial structure induces some positive agency costs

$$
\xi_{n}(0)=C_{n}(V(0), S(0), 0)-\Phi_{n}\left(V(0), S(0), 0 ; \mathcal{A}_{1}, \mathcal{A}_{2}, \cdots, \mathcal{A}_{n}\right) \geq 0
$$

Indeed, as the variational approach shows that $C_{n}(V(0), S(0), 0)$ is a maximum, agency costs are necessarily non negative. We now have to endogenise these exercise policies $\mathcal{A}_{1}, \cdots, \mathcal{A}_{n}$ as a function of the existing capital structure.

\subsection{The Agency Costs of a Zero Coupon Debt.}

This section studies the case of a levered firm financed with a zero coupon debt. Again, our objective is to characterise the agency costs associated with such a financial structure 
and we deliberately ignore the question of the optimality of this capital structure: given that we only focus on a cost of debt, the optimal amount of debt in our model will tautologically be zero. Our objective is to be able to derive an order of magnitude for this cost of debt which could then be compared with some possible benefits of debt. For instance, one can show that introducing some tax shields would make some strictly positive debt levels desirable.

Assume the firm is financed with a zero-coupon bond maturing at date $T$ with face value $M$. We suppose that if the firm is scrapped then the debt becomes immediately due (with the face value being correspondly discounted) or, equivalently that the proceeds of the residual value are invested in the riskless asset until date $T$ is reached. The only thing we rule out here is the possibility that equityholders could scrap the firm and run away with the residual value. This is in the spirit of the analysis first developed by Hart and Moore (1989) where the liquidation proceeds cannot be diverted by entrepreneurs.

The value of equity satisfies:

\section{Lemma 4}

(i) At date $t_{n}$, conditionally on the firm still being operated as an ongoing concern at that date, the value of the equity is $C\left(V\left(t_{n}\right), M, T-t_{n}\right)$.

(ii) For all $1 \leq i \leq n-1$, conditionally on the firm still being operated as an ongoing concern at date $t_{n-i}$, the value of the equities is

$C_{i}\left(V\left(t_{n-i}\right)+P\left(V\left(t_{n-i}\right), M, T-t_{n-i}\right), S\left(t_{n-i}\right), t_{n-i}\right)+e^{-(r-\delta)\left(t_{n-i+1}-t_{n-i}\right)} S\left(t_{n-i}\right)-M e^{-r\left(T-t_{n-i}\right)}$.

Proof: see appendix

The first part of this lemma simply restates the well-known result that, without any operating decision considerations (after date $t_{n}$ there is no pending scrapping dates), the value of equity in a levered firm is the value of a call option on the firm with an exercise price equal to the debt obligation. At an earlier date, equityholders also have the option 
to scrap the company before date $T$. Our expression obtains by rearranging terms and using the put-call parity formula. The intuition can be illustrated in the example of a 2 scrapping dates model: $t_{1}$ and $t_{2}$. The value of equity at date $t_{2}$ (the last scrapping date) conditionally on continuing at date $t_{2}$ is simply $C\left(V\left(t_{2}\right), M, T-t_{2}\right)$. Notice that equityholders will continue at date $t_{2}$ if $C\left(V\left(t_{2}\right), M, T-t_{2}\right) \geq\left(S\left(t_{2}\right)-M e^{-r\left(T-t_{2}\right)}\right)^{+}$and in particular, continuation will always takes place whenever $S\left(t_{2}\right) \leq M e^{-r\left(T-t_{2}\right)}$ as the value of a call is positive. The value of equity at date $t_{1}$ conditionally on continuing at date $t_{1}$ is:

$$
\mathbb{E}_{t_{1}}\left[e^{-r\left(t_{2}-t_{1}\right)}\left(\left(C\left(V\left(t_{2}\right), M, T-t_{2}\right)-S\left(t_{2}\right)+M e^{-r\left(T-t_{2}\right)}\right)^{+}+S\left(t_{2}\right)-M e^{-r\left(T-t_{2}\right)}\right)\right]
$$

which rewrites as (using the put-call parity formula):

$$
C\left(P\left(V\left(t_{1}\right), M, T-t_{1}\right)+V\left(t_{1}\right), S\left(t_{1}\right), t_{1}\right)+\mathbb{E}_{t_{1}}\left[e^{-r\left(t_{2}-t_{1}\right)}\left(S\left(t_{2}\right)-M e^{-r\left(T-t_{2}\right)}\right)\right]
$$

the formula given in the lemma. If they continue at date $t_{1}$, equityholders know that they will get at least $S\left(t_{2}\right)-M e^{-r\left(T-t_{2}\right)}$. Indeed, if this is negative they will not scrap at date $t_{2}$ and wait for $V(T)$ to realise as things can only get better from their point of view. If this expression is positive, they can always obtain this payoff by scrapping at date $t_{2}$. But they can sometimes do better by exchanging $S\left(t_{2}\right)-M e^{-r\left(T-t_{2}\right)}$ against $\mathbb{E}_{t_{2}}\left[(V(T)-M)^{+}\right]$. Hence, the value of equity if there is no scrapping at date $t_{1}$ is the expected value of $S\left(t_{2}\right)-M e^{-r\left(T-t_{2}\right)}$ plus the expected value of the exchange option which allows equityholders to swap $S\left(t_{2}\right)-M e^{-r\left(T-t_{2}\right)}$ for $\mathbb{E}_{t_{2}}\left[(V(T)-M)^{+}\right]$at date $t_{2}$. The first term of the formula represents the value of this exchange option.

¿From this lemma and the assumption that the management team chooses the operating policy maximising the equity value, we are now in position to prove:

\section{Proposition 2}

(i) Assume the firm is financed with a zero-coupon bond maturing at date $T$ with face value $M$, then the value of the firm at date 0 is defined by the relation

$$
v_{n}\left(V(0), S(0), 0 ; \mathcal{E}_{1}, \cdots, \mathcal{E}_{n}\right)=S_{0} e^{-(r-\delta) t_{1}}+\Phi_{n}\left(V(0), S(0), 0 ; \mathcal{E}_{1}, \cdots, \mathcal{E}_{n}\right)
$$


where

$$
\begin{aligned}
& \mathcal{E}_{n}=\left\{P\left(V\left(t_{n}\right), M, T-t_{n}\right)+V\left(t_{n}\right) \geq S\left(t_{n}\right)\right\} \\
& \text { and } \forall 1 \leq i \leq n-i \\
& \mathcal{E}_{n-i}=\left\{C_{i}\left(V\left(t_{n-i}\right)+P\left(V\left(t_{n-i}\right), M, T-t_{n-i}\right), S\left(t_{n-i)}\right), t_{n-i}\right) \geq \tilde{S}\left(t_{n-i}\right)\right\} .
\end{aligned}
$$

(ii) At each date $t_{n-i}$, (for all $0 \leq i \leq n-1$ ), equityholders "too often continue" the activity of the firm with respect to the first best rule.

Proof: see appendix.

Some comments are in order to illustrate the operating decisions of the equityholders of a levered company. At the last scrapping date, equityholders simply compare the value of their claim when the firm is closed, $\left(S\left(t_{n}\right)-M e^{-r\left(T-t_{n}\right)}\right)^{+}$, with the value under continuation. The value under continuation is the value of a call option on $V$ with an exercise price of $M$, as in Merton (1974). The expression for $\mathcal{E}_{n}$ comes from the put-call parity formula. Notice again that if the scrap value is insufficient to meet the discounted debt obligation, $\left(S\left(t_{n}\right) \leq M e^{-r\left(T-t_{n}\right)}\right)$, then necessarily equityholders will prefer to keep the option alive and therefore continue the firm's activities. The exercise policy of the equityholders of a levered firm at date $n-1$ can be understood with the same sort of thought experiment than the one we did in the unlevered case. Suppose that equityholders were sure to scrap the firm at date $t_{n}$. Under this assumption, their expected payoff if they continue at date $t_{n-1}$ is $\mathbb{E}_{t_{n-1}}\left[\left(S\left(t_{n}\right)-M e^{-r\left(T-t_{n}\right)}\right)^{+}\right]$. From our previous remark, this scenario is only possible under the hypothesis that equityholders consider as certain that $S\left(t_{n}\right) \geq M e^{-r\left(T-t_{n}\right)}$, otherwise closure will not occur at date $t_{n}$. If they think so, should they close the firm right now instead of waiting until the next possible date? In a fashion similar to what happened for the all-equity firm, the net gain of an earlier closure relative to a shut down at the next date remains equal to $\tilde{S}\left(t_{n-1}\right)$. This is again the difference between $S\left(t_{n-1}\right)-M e^{-r\left(T-t_{n-1}\right)}$ and the discounted value of $S\left(t_{n}\right)-M e^{-r\left(T-t_{n}\right)}$, i.e. $S\left(t_{n-1}\right) e^{-(r-\delta)\left(t_{n}-t_{n-1}\right)}-M e^{-r\left(T-t_{n-1}\right)}$. Indeed, the present value of the debt obligation is invariant to the date at which debt is repaid as it is simply the face value discounted at a rate $r$. The second effect governing the scrapping decision is different from the one in the 
first best case because now the equityholders' option is not to exchange $S\left(t_{n}\right)$ for $V\left(t_{n}\right)$ but $\left(S\left(t_{n}\right)-M e^{-r\left(T-t_{n}\right)}\right)+$ for $\mathbb{E}_{t_{n}}\left[(V(T)-M)^{+}\right]$. For instance, using the illustration of Lemma 4 of a two scrapping dates case, equityholders continue at date $t_{1}$ if the expected value of $S\left(t_{2}\right)-M e^{-r\left(T-t_{2}\right)}$ plus the expected value of the exchange option which allows equityholders to swap $S\left(t_{2}\right)-M e^{-r\left(T-t_{2}\right)}$ to $\mathbb{E}_{t_{2}}\left[(V(T)-M)^{+}\right]$exceeds $S\left(t_{1}\right)-M e^{-r\left(T-t_{1}\right)}$. Rearranging terms, using the definition of $C_{i}$ and the put-call parity formula, we obtain $\mathcal{E}_{2}$. Same arguments can be used to illustrate the derivation of $\mathcal{E}_{n-i}$.

How do these operating decisions compare with the first best policy? At the last scrapping date $t_{n}$, the excessive risk taking behaviour of equityholders is easy to characterise. In particular, as we have already mentioned, they will continue when the scrap value is less than the present value of debt, regardless of the difference $V-S$ : in such a case, stopping will force them to default while continuing keeps alive the chance that they will be able to repay their debt and collect whatever is left. This is a very inefficient decision rule if at the same time the current value $V\left(t_{n}\right)$ is much smaller than the residual value. Such a case corresponds to an extreme form of gamble for resurrection. In fact, this form of gamble will occur at any date $t_{n-i}$ when $S\left(t_{n-i}\right) \leq M e^{-r\left(T-t_{n_{i}}\right)}{ }^{15}$. But even in the alternative case, equityholders' behaviour will exhibit excessive continuation (at least weakly) compared to the first best policy, at every date $t_{n-i}$. In addition to the effect on the firm's value, the operating policy also affects the expected cost for equityholders of the debt repayment. If they close the firm when the scrap value exceeds the debt obligation, equityholders fully bear the cost of repaying their debt (the probability of default under such a scenario is zero). Keeping the firm alive allows them to decrease the cost the debt repayment as a state of default may occur latter. Compared to the first best policy which is only concerned with firm's value maximisation, this effect tilts the optimal decision towards more continuation. An important implication of this reasoning is that the debt capacity is less than in the case where the operating policy would be the first best one. As the firm's value is higher with the first best policy while the equity value is higher with the second best policy and as the sum of the debt and equity value equals the firm's value, necessarily the debt value is reduced. Hence, that implies that yield spreads are

\footnotetext{
${ }^{15}$ This is easily deduced from Lemma 3 .
} 
higher than what one would obtain when ignoring the agency conflict, i.e. assuming a first best operating policy.

\subsection{Comparative Statics}

We now investigate how agency costs vary with leverage, time and the number of possible scrapping dates.

How does the face value of debt affect the equityholders' incentives to engage in excessive continuation? We deduce from proposition 2 :

Corollary 2 The value of the agency costs associated with a zero coupon debt increases with the face value of debt, $M$.

Proof: see appendix.

Comparing the first and second best operating sets, one observes that they only coincide when $M$ goes to zero and that the difference between the two increases with the leverage. First a higher leverage makes it more likely that the discounted face value of debt exceeds the scrapping value which leads equityholders to continue independently of the value of productive assets. But even in the opposite case where the debt can be entirely repaid if the firm is scrapped do we observe more excessive continuation when $M$ gets larger. Following the previous intuition according to which continuing is a way to reduce the expected cost of repaying the debt, a higher leverage makes it even more valuable for equityholders to continue as this motive is more important. Alternatively, one can say that equityholders are more prone to take on risks as only substantial upturns are needed for them to get some returns out of the company when $M$ is larger. Hence, the model predicts that agency costs and consequently yield spreads to be higher for firms with higher levels of leverage.

Another question of interest concerns the evolution of agency costs over time. In particular, it is often argued that risk-taking behaviour is more of a problem when the firm gets closer to the debt maturity. Equityholders can have a better idea of the likelihood 
that they will be able to repay the debt and, in case the financial situation looks rather difficult, may be more willing to engage in excessive risk taking. Note that in the case $\delta \geq r$, the answer to the question is very simple: at any date different from the last one, we have seen that the firm's operations are continued in the first best but this is also true in the second best as $\tilde{S}\left(t_{i}\right) \leq 0$. It is always optimal to wait until the last possible scrapping date for making a decision. Indeed, there is no cost to keep the option to scrap the firm alive until this last date ${ }^{16}$. Not scrapping today for possibly scrapping the firm at the last date can be viewed as an investment which yields an expected return of $\delta$. This is better than scrapping now and investing the proceeds in the riskless asset at a rate $r$. Whatever the number of scrapping dates, the only one which is relevant is the last one and so agency costs are fully determined by the deviation of the operating policy due to debt at this last date. Using optimal stopping representation, one can prove this property still holds if the scrapping decision can be taken in continuous time. This result can be seen as the symmetric of the one derived for instance in Dixit and Pindyck (1994) page 148: under a risk neutrality assumption, if the riskless rate of return is less than the instantaneous expected return of a project, the firm will be better off waiting and will never invest. Of course, considering a continuous scrapping decision means that we are concerned with the valuation of an American type exchange option. Explicit pricing formula only exist for infinite maturity ${ }^{17}$. Carr (1988) proposes to use the methodology of Geske and Johnson (1984) applied to compound exchange options to approximate the value of an American type exchange option with finite maturity. We simply note here that the variational methodology we develop imply potential improvements of this numerical procedure. If the operating policies coincide at $n-1$ dates, there is however at the last date excessive continuation. We can thus conclude that in this somehow degenerated case, excessive continuation is possibly a problem only when the firm gets very close to the maturity.

In the case $\delta \leq r$, simplifying slightly the model by assuming that the scrap value is

\footnotetext{
${ }^{16}$ The fact that $t_{n} \leq T$ introduces a cost of not scrapping at the last possible date: this option is then irremediably lost. If $t_{n}=T$, this cost also disappears and whatever the capital structure, the decision taken at $T$ is efficient.

${ }^{17}$ see for instance Gerber and Shiu (1996).
} 
deterministic, we can also show the following corollary of Proposition 2:

Corollary 3 The continuation policy chosen by equityholders of a leveraged company (continue iff $\omega_{i} \in \mathcal{E}_{n-i}$ ) departs more and more from the first best policy (continue iff $\left.\omega_{i} \in \mathcal{A}^{\star}{ }_{n-i}\right)$ if and only if:

$$
P\left(\widehat{V}_{n-i-1}^{S B}, M, T-t_{n-i-1}\right)<P\left(\widehat{V}_{n-i}^{S B}, M, T-t_{n-i}\right)
$$

where, $\widehat{V}_{n-i}^{S B}$ is implicitly defined for all $0 \leq i \leq n-1$ by the relation:

$$
\left.C_{i}\left(\widehat{V}_{n-i}^{S B}+P\left(\widehat{V}_{n-i}^{S B}, M, T-t_{n-i}\right), S\left(t_{n-i}\right), t_{n-i}\right)-\widetilde{S}\left(t_{n-i}\right)\right)=0
$$

Proof: see appendix

When only the current value is stochastic, both the first best and the second best policies reduce to a simple threshold rule: continue at date $t_{i}$ whenever the current value $V\left(t_{i}\right)$ is high enough. Equation (3) characterizes the threshold of the current value of the firm's assets beyond which equityholders of a leveraged company choose to continue the activity of the firm at date $t_{n-i}$. The proof of corollary 3 developped in appendix shows that (i) the threshold chosen by the equityholders of a leveraged company is higher than the one which would prevail in the absence of debt, (this clearly illustrates the excessive continuation problem) and that (ii) the difference between these two thresholds, (that is the evolution of agency costs), is simply governed by the evolution of the value of a put option. Remark that since the value of a put is not a monotonic function of its maturity, the evolution of agency costs is not fully explicit.

The next proposition characterises (in the general case) how the difference between the first best decision rule and the second best one evolves with the number of possible scrapping dates, $n$.

\section{Proposition 3}

(i) If the riskless interest rate is lower than the instantaneous return of the scrap value of the firm's assets $(r \leq \delta)$ then the agency costs of debt are independent of $n$, the number of possible scrapping dates. 
(ii) If the riskless interest rate is higher than the instantaneous return of the scrap value of the firm's assets $(r>\delta)$ then the agency costs of debt increase with $n$.

Proof: see appendix.

When $\delta \geq r$, we have seen that it is always optimal to wait until the last possible scrapping date for making a decision. The number of scrapping pending dates is thus irrelevant. When $\delta \leq r$, the second best as well as the first best may call for an early closure. We know that the magnitude of the agency costs is given by the difference between two compound options:

$$
\xi_{n}(0)=C_{n}(V(0), S(0), 0)-\Phi_{n}\left(V(0), S(0), 0 ; A_{1}, A_{2}, \ldots, A_{n}\right) .
$$

Adding a new scrapping date induces a new composition of the "initial" compound options. Thus, both term of the difference (4) decrease when $n$ increases. Our proposition says that the second term of (4) decreases relatively more than the first term. The intuition is simple: adding a new scrapping date does not introduce any new inefficiency in the policy of the first best firm (by definition) while it does so in the second best. Moreover these additional distortions cannot compensate for each other as they all go in the same direction, i.e. excessive continuation.

We now investigate some possibilities to reduce these distortions.

\section{Limiting Excessive Continuation.}

\subsection{The Role of Renegotiation.}

In presence of inefficiencies, we may expect rational economic agents to renegotiate contracts in a Pareto improving way. The contract theory literature has indeed emphasized the importance of renegotiation when predicting the consequences of different contractual arrangements. In a continuous time model with some exogenous bankruptcy costs, the papers of Leland (1994), Leland and Toft (1996), Anderson and Sundaresan (1996), or Mella-Barral (1999) have introduced the possibility that following a default, debtholders and equityholders renegotiate the debt contract to limit these costs. These papers have 
shown how such a possibility creates a scope for strategic default and how it modifies for instance the spread associated with defaultable bonds. However, the existence of significant direct bankruptcy costs, essential for these results, seems to be challenged by the empirical evidence which typically concludes to an order of magnitude in the range of $3-5 \%$ of the firm value for these costs.

In our model, there is a role for renegotiation even when assuming that direct bankruptcy costs are null. Indeed, renegotiation may occur to eliminate the (endogenous) agency costs of debt. We start by studying the benchmark case where renegotiation takes place without friction and at zero cost.

Suppose that at every date, the debtholders can get together and collectively offer to pay an amount $R_{t}$ to the equityholders if they accept to close the firm at the next scrapping date. The scenario in which they pay the equityholders for continuing is irrelevant because the previous section has shown that equityholders never engage in excessive liquidation $^{18}$. What does the sequence of renegotiation offers look like and are agency costs fully eliminated?

The minimum $R_{t}$ that equityholders will accept has to be such that their payoff when closure occurs plus this extra transfer is equal to their payoff under continuation. Deriving this amount and examining the conditions under which debtholders make such an offer allows us to show:

\section{Proposition 4}

(i) Renegotiation occurs anytime the realisation of $S$ and $V$ are such that the first best policy calls for a shut-down while equityholders would continue without renegotiation. Hence, excessive continuation is eliminated.

(ii) Compared to a world without agency conflicts, debt capacity is reduced.

Proof: see appendix

\footnotetext{
${ }^{18}$ We also need that debtholders never want too continue more often than equityholders would like to. One can check that debtholders would choose an operating regime characterised by excessive closure compared to the first best.
} 
The possibility of costless renegotiation eliminates the inefficiencies but is not equivalent to a situation where agency conflicts would be inexistent. For a given face value of debt, debtholders have to give up some payoffs if they want to renegotiate. Hence, the existence of a potential conflict over the operating policy reduces the debt capacity. The proof in the appendix assumes that debtholders give a transfer $R_{t}$ as small as possible. Of course, if equityholders have the bargaining power they may force debtholders to greater concessions which would reduce the debt capacity even more. Therefore, the results do not depend on the respective bargaining powers.

The dynamics of the renegotiation offers are very simple: whenever the value of $V$ and $S$ are such that the first best would call for a closure at that date and that equityholders are better off under continuation, renegotiation takes place. The renegotiation offer always takes the same form: debtholders propose to stop the activity and accept to pay a transfer to the equityholders for taking this decision. Therefore, a renegotiation strategy where debtholders accept some excessive continuation at the beginning, knowing that they will renegotiate latter on, is dominated. The first best is restored because renegotiation takes place under symmetric information: as it is standard in contract theory, the absence of asymmetric information guarantees that renegotiation reaches a Pareto efficient outcome.

As we said, the previous result should be considered as a benchmark, i.e. the outcome in a world where renegotiation takes place at no cost whenever some inefficient decisions are about to be taken. In practice, these conditions are unlikely to be fulfilled and one may ask what sort of mechanisms could help implement this form of renegotiation. Assuming that debtholders could be able to solve any coordination and free-riding problems when making offers (i.e. supposing some sort of representative debtholders is delegated the task to bargain with the equityholders), one practical mechanism would be to promise a debt discount to equityholders as a reward for early closure. For instance, debtholders could decrease the face value $M$ to $\tilde{M}$ such that equityholders have a proper incentive to shut the firm down. Such a solution would require debt concessions which are both time dependent and conditional on the current state of the world defined by $V\left(t_{n-i}\right), S\left(t_{n-i}\right)$.

This dependence on time and states of the world rules out the possibility to implement 
the first best by a contract which would specify a schedule of anticipated debt repayments (equal to what the representative debtholder would offer to equityholders). Moreover, one cannot design a debt contract which would induce an efficient shift of control, i.e. a transfer of control to the party more likely to take a decision in conformity with the first best rule. This is in contrast with the results obtained by Dewatripont and Tirole (1993) who show that a debt contract can be optimally designed to induce the choice of an appropriate abandonment decision. The difference lies in the dynamic and stochastic structure of the models. The optimal arrangement in one state at one particular date is typically not optimal at another date. Given the structure of the model, the contract will have to be fine-tuned to have a chance to implement the first best. A simple debt contract fails to achieve that because debt repayments cannot be contingent on the difference between the current and the residual value of the firm's assets.

When renegotiation is difficult to implement, different contractual arrangements can help trigger it and can reduce inefficiencies. The design of debt covenants, the time profile of coupons or the maturity structure are some key elements in that respect. The next sections will analyse in more detail the last two possibilities but we briefly discuss here the role of covenants.

The ideal covenant would specify that the firm should be closed whenever the first best rule calls for a shut down. For instance, at date $t_{n}$, this covenant should say that the firm is closed if and only if $S\left(t_{n}\right) \leq V\left(t_{n}\right)$. As this example highlights, this sort of covenant would require that a court of justice be able to verify both the value of $V$ and $S$. When the residual value of the assets is difficult to determine without closing the firm, the court may be unable to enforce such covenants. A common class of covenants specifies some minimum net worth requirement. In our model, this would imply that whenever $v(t)$, the value of the firm at date $t$, is lower than a threshold $\underline{v}$, bankruptcy is triggered. Again, we cannot expect to implement the first best as such a cut-off rule is not contingent on the difference $V(t)-S(t)$. Moreover, once they are in control, debtholders do not choose an operating rule corresponding to the first best. The operating decision which maximises the value of their claim typically exhibits too much conservatism. For instance, they will immediately shut the firm down when $S\left(t_{i}\right) \geq M e^{-r\left(T-t_{i}\right)}$, regardless 
of $V\left(t_{i}\right)$. Whether or not this type of covenant can increase the firm's value depends on the relative inefficiency of the equityholders' operating regime compared to the one that debtholders would choose.

\subsection{The Role of Coupons}

So far, we have limited our analysis to the case of a zero coupon. The objective of this section is to remove this assumption and to analyse the consequences of the existence of coupons on the agency costs. This is a question which can only be addressed in a non-stationary model: can debt payments be allocated over time in a way which reduces agency costs?

For tractability reason, we assume that there are two possible scrapping dates $\left(t_{1}\right.$ and $t_{2}$ ) and that a coupon $M_{1}$ is paid at a date $t_{1}+\tau$ between $t_{1}$ and $t_{2}\left(0<\tau<t_{2}-t_{1}\right)$. The rest of the debt $M_{2}$ is repaid at date $T$.

We suppose that to repay the first coupon, new equity is issued ${ }^{19}$. Bankruptcy is modelled as in Geske $(1977)^{20}$ : whenever new equity cannot be raised to repay the coupon, the ownership of the company is transfered to debtholders. This implies that they are now entitled both to the income rights and the control rights. In particular, they are in charge of the operating decisions at any pending scrapping date.

We consider the case where total indebtedness is held constant, i.e. $M_{1} e^{r\left(T-t_{1}-\tau\right)}+$ $M_{2}=M$ and we vary $M_{1}$ and $M_{2}$. For instance, if $M_{1}=0$ or $M_{2}=0$ we are back to a zero coupon case. We can then show:

\section{Proposition 5}

An increase in $M_{1}$ while keeping the total indebtedness $M_{1} e^{r\left(T-t_{1}-\tau\right)}+M_{2}=M$ constant, reduces the agency costs and increases the firm's value.

Proof: see appendix.

\footnotetext{
${ }^{19}$ In that case, old and new equityholders are treated in the same way.

${ }^{20}$ see also for instance Leland (1994)
} 
The introduction of a coupon affects the gamble for resurrection and the agency costs in a non trivial way. Equityholders take different decisions at date $t_{1}$ and at date $t_{2}$ and both are affected when $M_{1}$ increases. Moreover, the probability that debtholders, as opposed to equityholders, are in control at date $t_{2}$ is also modified.

The somehow degenerated case $\delta \geq r$ is useful for starting to illustrate the intuition behind this last proposition. In that case, both decision rules, first and second best, call for no scrapping at date 1 . Consequently, equityholders always take the efficient decision at date $t_{1}$. The only concern is to reduce the agency costs coming from the operating decision taken at date 2. Whether or not equityholders stay in control does not modify the effect. Suppose they do: a higher coupon implies a lower $M_{2}$ and from corollary 2, a less distorted continuation set. If now, bankruptcy is triggered at date $t_{1}+\tau$, debtholders are fully residual claimants and continue at date $t_{2}$ if and only if it is efficient to do so. Notice that one would like to increase the probability of bankruptcy in this scenario: equityholders, contrary to debtholders, adopt a suboptimal operating strategy at date $t_{2}$ are less likely to be in charge when $M_{1}$ increases. Optimally, the debt should be a zero coupon bond with a short maturity. In fact, this comes from the fact that bankruptcy reunifies the different claims and put them in only one hand. The multiplicity of claimholders is the root of excessive continuation: like an externality problem, equityholders do not take into account the consequences of the continuation decision on debtholders' claim value. Following bankruptcy, this externality is internalised.

The case where $\delta \leq r$ is more complicated but the previous conclusion is even stronger. The first thing to remark is that again the operating policy at date $t_{2}$ is closer to the first best one when $M_{1}$ increases for the same reasons as the one just discussed. More surprisingly, an increase in $M_{1}$ also reduces the departure in the operating policy from the first best one at date $t_{1}$. The reason is that an increase in $M_{1}$ at total indebtedness constant reduces the value of equity conditional on continuation at date $t_{1}$. There are two effects to distinguish: first, if the operating decision at date $t_{2}$ was exogenously given, paying a coupon decreases the value of equity under continuation at $t_{1}$ because it increases the risk of default at $t_{1}+\tau$ : keeping $M$ constant, increasing the coupon makes it more likely that the firm will go bankrupt as in Geske (1979). But there is a second effect which is 
that the operating policy at date $t_{2}$ will also be modified. As emphasized in the discussion of Lemma 4 , the value of equity at date $t_{1}$ is composed not only by the scrap value net of the debt repayments but also by the exchange option which allows equityholders to swap at date $t_{2},\left(S\left(t_{2}\right)-M_{2} e^{-r\left(T-t_{2}\right)}\right)^{+}$for $C\left(V\left(t_{2}\right), M_{2}, T-t_{2}\right)$. The value of this option increases with $M_{2}$. An increase in $M_{1}$ with $M$ constant implies a decrease in $M_{2}$ and hence a reduction of this option value. This effect thus reinforces the effect due to default risk to reduce even further the value of equity at date $t_{1}$ conditionally on not scrapping at that date. However, the value of equity if scrapping occurs at that date is independent of the allocation of coupons: the whole debt (with some proper discounting) becomes due. As a consequence, the introduction of a coupon makes equityholders less willing to continue at date $t_{1}$. As there is excessive continuation compared to the first best, this is a benefit of designing a debt contract with a coupon.

This reduction of the gamble incentives at date $t_{1}$ is however insufficient to fully eliminate the excessive continuation problem. The reason is still that although the debt becomes fully due if they stop at date $t_{1}$, equityholders will repay it after having continued at date $t_{1}$ only if the firm's value if high enough. Hence, if they continue they reduce the expected cost of repaying the debt, which compared with the first best tilts their decision toward more continuation.

¿From the previous proposition, we deduce the following corollary about the debt capacity:

Corollary 4 An increase in $M_{1}$ while keeping the total indebtedness $M_{1} e^{r\left(T-t_{1}-\tau\right)}+M_{2}=$ $M$ constant, increases the debt capacity.

For a given operating policy, an increase in $M_{1}$ with $M$ constant reduces the value of equity (more precisely, it reduces the equity value if continuation takes place at $t_{1}$ and leaves it unchanged otherwise). The previous proposition has shown that the firm's value increases, so for these two reasons the market value of the debt at date 0 is increased. This result has some implications for the evolution of yields on defaultable bonds. Not only the payment of coupons modifies the default risk but it also affects the "gambling risk". The reduction in agency costs impact positively on the debt capacity and hence 
reduces the spread with risk-free yields, compared to a model which ignores agency costs.

\section{Conclusion}

This paper has characterised the agency costs of debt due to excessive continuation by equityholders in a continuous time environment. As such, it offers a dynamic extension of so far mainly static models in corporate finance. The paper makes a step toward an analysis of the magnitude of these costs by deriving a quasi-closed form for agency costs. At a conceptual level, we have analysed how leverage distorts the operating decisions taken by equityholders, given that the continuation decision has some option value in the stochastic environment considered. We have also analysed the evolution of these agency conflicts as time passes. Adopting a non stationary model has allowed us to address questions like the optimal allocation of coupons over time and to investigate the sequence of renegotiation offers made in equilibrium. We have shown that the agency costs can be fully eliminated with renegotiation taking place anytime the second best policy differs from the first best although compared to this first best world, the debt capacity is reduced. The introduction of coupons also proved to be effective to limit excessive continuation. Coupons now affect not only the default risk but also the "gambling risk". 


\section{Appendix}

\section{Proof of Proposition 1}

Under risk neutrality, for a given continuation policy $\mathcal{A}_{1}, \cdots, \mathcal{A}_{n}$, the value, $v_{n}\left(V(0), S(0), 0 ; \mathcal{A}_{1}, \cdots, \mathcal{A}_{n}\right)$, of the firm at date 0 is

$$
\begin{aligned}
v_{n}\left(V(0), S(0), 0 ; \mathcal{A}_{1}, \cdots, \mathcal{A}_{n}\right) & =\mathbb{E}\left[e^{-r t_{1}} S\left(t_{1}\right)\left(1-\mathbb{I}_{\mathcal{A}_{1}}\right)\right] \\
& +\sum_{i=2}^{n} \mathbb{E}\left[e^{-r t_{i}} S\left(t_{i}\right)\left(1-\mathbb{I}_{\mathcal{A}_{i}}\right) \mathbb{I}_{\mathcal{A}_{1}} \cdots \mathbb{I}_{\mathcal{A}_{i-1}}\right] \\
& +\mathbb{E}\left[e^{-r t_{n}} V\left(t_{n}\right) \mathbb{I}_{\mathcal{A}_{1}} \cdots \mathbb{I}_{\mathcal{A}_{n}}\right] .
\end{aligned}
$$

This can be re-written under the form

$$
\begin{aligned}
v_{n}\left(V(0), S(0), 0 ; \mathcal{A}_{1}, \cdots, \mathcal{A}_{n}\right) & =e^{-(r-\delta) t_{1}} S_{0}+\left\{\mathbb { E } \left[e^{-r t_{n}}\left(V\left(t_{n}\right)-S\left(t_{n}\right)\right) \mathbb{I}_{\mathcal{A}_{1} \cap \cdots \cap \mathcal{A}_{n}}\right.\right. \\
& \left.+\sum_{i=1}^{n-1} \mathbb{E}\left[e^{-r t_{i}} \tilde{S}\left(t_{i}\right) \mathbb{I}_{\mathcal{A}_{1} \cap \cdots \cap \mathcal{A}_{i}}\right]\right\} .
\end{aligned}
$$

The proposition is then a direct consequence of lemma 1 and lemma 2 .

\section{Proof of Lemma 4}

(i) is obvious

(ii) is proved by induction on $i$. For $i=1$, under the continuation decision, the value of the equities at date $t_{n-1}$ is

$$
\begin{aligned}
& \mathbb{E}_{t_{n-1}}\left[e^{-r\left(t_{n}-t_{n-1}\right)} \max \left\{\left(S\left(t_{n}\right)-M e^{-r\left(T-t_{n}\right)}\right)^{+}, C\left(V\left(t_{n}\right), M, T-t_{n}\right)\right\}\right] \\
& =\mathbb{E}_{t_{n-1}}\left[e^{-r\left(t_{n}-t_{n-1}\right)} \max \left\{S\left(t_{n}\right)-M e^{-r\left(T-t_{n}\right)}, C\left(V\left(t_{n}\right), M, T-t_{n}\right)\right\}\right] \\
& =\mathbb{E}_{t_{n-1}}\left[e^{-r\left(t_{n}-t_{n-1}\right)} \max \left\{S\left(t_{n}\right), V\left(t_{n}\right)+P\left(V\left(t_{n}\right), M, T-t_{n}\right)\right\}\right]-M e^{-r\left(T-t_{n-1}\right)} \\
& =\mathbb{E}_{t_{n-1}}\left[e^{-r\left(t_{n}-t_{n-1}\right)} \max \left\{V\left(t_{n}\right)+P\left(V\left(t_{n}\right), M, T-t_{n}\right)-S\left(t_{n}\right), 0\right\}\right] \\
& \quad+S\left(t_{n-1}\right) e^{-(r-\delta)\left(t_{n}-t_{n-1}\right)}-M e^{-r\left(T-t_{n-1}\right)} \\
& =C_{1}\left(V\left(t_{n-1}\right)+P\left(V\left(t_{n-1}\right), M, T-t_{n-1}\right), S\left(t_{n-1}\right), t_{n-1}\right)+S\left(t_{n-1}\right) e^{-(r-\delta)\left(t_{n}-t_{n-1}\right)}-M e^{-r\left(T-t_{n-1}\right)} .
\end{aligned}
$$


where the first equality comes from the positivity of the price of a call option and the second equality comes from the put-call parity formula.

Using the induction property and similar calculations as in the first part of the proof, it is easy to see that the value fo the equities at date $t_{n-i-1}$ under the continuation policy verifies the equality :

$$
\begin{aligned}
& \mathbb{E}_{t_{n-i-1}}\left[e ^ { - r ( t _ { n - i } - t _ { n - i - 1 } ) } \operatorname { m a x } \left\{\left(S\left(t_{n-i}\right)-M e^{-r\left(T-t_{n-i}\right)}\right)^{+},\right.\right. \\
& C_{i}\left(V\left(t_{n-i}\right)+P\left(V\left(t_{n-i}\right), M, T-t_{n-i}\right), S\left(t_{n-i}\right), t_{n-i}\right) \\
& \left.\left.+e^{-(r-\delta)\left(t_{n-i+1}-t_{n-i}\right)} S\left(t_{n-i}\right)-M e^{-r\left(T-t_{n-i}\right)}\right\}\right] \\
& =C_{i+1}\left(V\left(t_{n-i-1}\right)+P\left(V\left(t_{n-i-1}\right), M, T-t_{n-i-1}\right), S\left(t_{n-i-1}\right), t_{n-i-1}\right) \\
& +e^{-(r-\delta)\left(t_{n-i}-t_{n-i-1}\right)} S\left(t_{n-i-1}\right)-M e^{-r\left(T-t_{n-i-1}\right)}
\end{aligned}
$$

\section{Proof of Proposition 2}

For the first part of the proposition, we just have to prove that

$$
\begin{aligned}
& \forall 1 \leq i \leq n-1 \\
& \mathcal{E}_{n-i}=\left\{C_{i}\left(V\left(t_{n-i}\right)+P\left(V\left(t_{n-i}\right), M, T-t_{n-i}\right), S\left(t_{n-i}\right), t_{n-i}\right) \geq \tilde{S}\left(t_{n-i}\right)\right\} .
\end{aligned}
$$

¿From lemma 3 and lemma 4, equityholders decide to continue at date $t_{n-i}(\forall 1 \leq i \leq n-1)$ if and only if

$$
\begin{aligned}
& C_{i}\left(V\left(t_{n-i}\right)+P\left(V\left(t_{n-i}\right), M, T-t_{n-i}\right), S\left(t_{n-i}\right), t_{n-i}\right) \\
& \quad+e^{-(r-\delta)\left(t_{n-i+1}-t_{n-i}\right)} S\left(t_{n-i}\right)-M e^{-r\left(T-t_{n-i}\right)} \geq S\left(t_{n-i}\right)-M e^{-r\left(T-t_{n-i}\right)},
\end{aligned}
$$

or equivalently

$$
C_{i}\left(V\left(t_{n-i}\right)+P\left(V\left(t_{n-i}\right), M, T-t_{n-i}\right), S\left(t_{n-i}\right), t_{n-i}\right) \geq \tilde{S}\left(t_{n-i}\right) .
$$

The second part of the proposition can be proved by remarking that for all $0 \leq i \leq n-1$ $\mathcal{A}_{n-i}^{*} \subset \mathcal{E}_{n-i}$, as the value of a put is non negative. The property is obvious for $i=0$. For $1 \leq i \leq n-1$, the inclusion is easily verified by induction on $i$ and by comparing at each exercise date the payoff of the two compound exchange options which define the sets $\mathcal{A}_{n-i}^{*}$ and $\mathcal{E}_{n-i}$. 
This ends the proof.

\section{Proof of Corollary 2}

Corollary 2 is a consequence of the following lemma

Lemma 5 Let $\mathcal{A}_{i}$ and $\mathcal{A}_{i}^{\prime}$ two sequences of $\mathcal{F}_{t_{i}}$ measurable subsets for $i=1, n$. Assume $\mathcal{A}_{i}^{*} \subset \mathcal{A}_{i} \subset \mathcal{A}_{i}^{\prime}$ then

$$
\Phi_{n}\left(V(0), S(0), 0, \mathcal{A}_{1}, \ldots, \mathcal{A}_{n}\right)>\Phi_{n}\left(V(0), S(0), 0, \mathcal{A}_{1}^{\prime}, \ldots, \mathcal{A}_{n}^{\prime}\right)
$$

\section{Proof of Lemma 5}

By induction on $n$ : For $n=1$, since $\left(\mathcal{A}_{1}^{\prime}-\mathcal{A}_{1}\right) \cap \mathcal{A}_{1}^{*}=\emptyset$, we have

$$
\Phi_{1}\left(V(0), S(0), 0, \mathcal{A}_{1}^{\prime}\right)-\Phi_{1}\left(V(0), S(0), 0, \mathcal{A}_{1}\right)=\mathbb{E}\left[e^{-r t_{1}}\left(V\left(t_{1}\right)-S\left(t_{1}\right)\right) \mathbb{1}_{\mathcal{A}_{1}^{\prime}-\mathcal{A}_{1}}\right]<0 .
$$

Suppose now the lemma true for $n-1$.

$$
\begin{aligned}
\Phi_{n}\left(V(0), S(0), 0, \mathcal{A}_{1}, \ldots, \mathcal{A}_{n}\right)= & \mathbb{E}\left[e^{-r t_{1}}\left(\Phi_{n-1}\left(V(0), S(0), 0, \mathcal{A}_{2}, \ldots, \mathcal{A}_{n}\right)-\tilde{S}\left(t_{1}\right)\right) \mathbb{I}_{\mathcal{A}_{1}}\right] \\
> & \mathbb{E}\left[e^{-r t_{1}}\left(\Phi_{n-1}\left(V(0), S(0), 0, \mathcal{A}_{2}^{\prime}, \ldots, \mathcal{A}_{n}^{\prime}\right)-\tilde{S}\left(t_{1}\right)\right) \mathbb{I}_{\mathcal{A}_{1}}\right] \\
> & \mathbb{E}\left[e^{-r t_{1}}\left(\Phi_{n-1}\left(V(0), S(0), 0, \mathcal{A}_{2}^{\prime}, \ldots, \mathcal{A}_{n}^{\prime}\right)-\tilde{S}\left(t_{1}\right)\right) \mathbb{I}_{\mathcal{A}_{1}}\right] \\
& +\mathbb{E}\left[e^{-r t_{1}}\left(\Phi_{n-1}\left(V(0), S(0), 0, \mathcal{A}_{2}^{\prime}, \ldots, \mathcal{A}_{n}^{\prime}\right)-\tilde{S}\left(t_{1}\right)\right) \mathbb{I}_{\left.\mathcal{A}^{\prime}{ }_{1}-\mathcal{A}_{1}\right]}\right. \\
= & \mathbb{E}\left[e^{-r t_{1}}\left(\Phi_{n-1}\left(V(0), S(0), 0, \mathcal{A}_{2}^{\prime}, \ldots, \mathcal{A}_{n}^{\prime}\right)-\tilde{S}\left(t_{1}\right)\right) \mathbb{I}_{\mathcal{A}_{1}^{\prime}}\right] \\
= & \Phi_{n}\left(V(0), S(0), 0, \mathcal{A}_{1}^{\prime}, \ldots, \mathcal{A}_{n}^{\prime}\right) .
\end{aligned}
$$

The first inequality comes from the induction assumption. For the second inequality, simply remark that $\mathcal{A}_{1}^{\prime}-\mathcal{A}_{1} \cap \mathcal{A}_{1}^{*}=\emptyset$ and thus

$$
\left(\Phi_{n-1}\left(V(0), S(0), 0, \mathcal{A}_{2}^{\prime}, \ldots, \mathcal{A}_{n}^{\prime}\right)-\tilde{S}\left(t_{1}\right)\right) \mathbb{1}_{\mathcal{A}^{\prime}{ }_{1}-\mathcal{A}_{1}}<0 \text { a.s }
$$

Corollary 2 is then a direct consequence of assertion (ii) of proposition 2 .

\section{Proof of Corollary 3}


Assume the scrap value $S$ being deterministic, using comparative statics results on compound exchange option ${ }^{21}$ we verify that the continuation sets for the first best rule and for the second best rule can now be re-written:

$$
\begin{aligned}
& \mathcal{A}_{n-i}^{*}=\left\{V\left(t_{n-i}\right) \geq \widehat{V}_{n-i}^{F B}\right\}, \quad \forall 0 \leq i \leq n-1, \\
& \mathcal{E}_{n-i}=\left\{V\left(t_{n-i}\right) \geq \widehat{V}_{n-i}^{S B}\right\}, \quad \forall 0 \leq i \leq n-1 .
\end{aligned}
$$

where, $\widehat{V}_{n-i}^{F B}$, ( resp. $\left.\widehat{V}_{n-i}^{S B}\right)$ is implicitly defined for all $0 \leq i \leq n-1$ by the relation:

$$
\varphi_{i}^{F B}\left(\widehat{V}_{n-i}^{F B}\right)=0
$$

where $\varphi_{i}^{F B}(V)=C_{i}\left(V, S\left(t_{n-i}\right), t_{n-i}\right)-\widetilde{S}\left(t_{n-i}\right) . \quad\left(\operatorname{resp} . \quad \varphi_{i}^{S B}\left(\widehat{V}_{n-i}^{S B}\right)=0\right.$, where $\left.\varphi_{i}^{S B}(V)=C_{i}\left(V+P\left(V, M, T-t_{n-i}\right), S\left(t_{n-i}\right), t_{n-i}\right)-\widetilde{S}\left(t_{n-i}\right)\right)$.

With $\delta<r$, we have:

$$
0<\widehat{V}_{n-i}^{S B}<\widehat{V}_{n-i}^{F B} \quad \forall 0 \leq i \leq n-1
$$

We want to prove

$$
\widehat{V}_{n-i-1}^{F B}-\widehat{V}_{n-i-1}^{S B}<\widehat{V}_{n-i}^{F B}-\widehat{V}_{n-i}^{S B} \Leftrightarrow P\left(\widehat{V}_{n-i-1}^{S B}, M, T-t_{n-i-1}\right)<P\left(\widehat{V}_{n-i}^{S B}, M, T-t_{n-i}\right) .
$$

Using again monotonicity properties of the functions $\varphi_{i}^{F B}$ and $\varphi_{i}^{S B}$ :

$$
\begin{array}{lll} 
& \widehat{V}_{n-i-1}^{F B}-\widehat{V}_{n-i-1}^{S B}<\widehat{V}_{n-i}^{F B}-\widehat{V}_{n-i}^{S B} \\
\Leftrightarrow & \varphi_{i}^{F B}\left(\widehat{V}_{n-i-1}^{F B}-\widehat{V}_{n-i-1}^{S B}+\widehat{V}_{n-i}^{S B}\right)<0 \\
\Leftrightarrow & \widehat{V}_{n-i-1}^{F B}-\widehat{V}_{n-i-1}^{S B}<P\left(\widehat{V}_{n-i}^{S B}, M, T-t_{n-i}\right) \\
\Leftrightarrow & \widehat{V}_{n-i-1}^{F B}<\widehat{V}_{n-i-1}^{S B}+P\left(\widehat{V}_{n-i}^{S B}, M, T-t_{n-i}\right) \\
\Leftrightarrow \quad & \varphi_{i+1}^{F B}\left(\widehat{V}_{n-i-1}^{S B}+P\left(\widehat{V}_{n-i}^{S B}, M, T-t_{n-i}\right)\right)>0 \\
\Leftrightarrow \quad & P\left(\widehat{V}_{n-i-1}^{S B}, M, T-t_{n-i-1}\right)<P\left(\widehat{V}_{n-i}^{S B}, M, T-t_{n-i}\right) .
\end{array}
$$

The second equivalence comes from the relation

$C_{i}\left(\widehat{V}_{n-i-1}^{F B}-\widehat{V}_{n-i-1}^{S B}+\widehat{V}_{n-i}^{S B}, S\left(t_{n-i}\right), t_{n-i}\right)<\tilde{S}\left(t_{n-i}\right)=C_{i}\left(V_{n-i}^{S B}+P\left(\widehat{V}_{n-i}^{S B}, M, T-t_{n-i}\right), S\left(t_{n-i}\right), t_{n-i}\right)$.

\footnotetext{
${ }^{21}$ Throughout this proof we use the increasness of the price of a compound exchange option $C_{n}(X(t), S(t), t)$ with respect to the underlying price $X(t)$. Carr (1988) first proves this result for a composition of two exchange options. A calculus based on our lemma 2 and on the envelop theorem allows us to generalize the Carr's result to the case of a composition of $n$ exchange options.
} 
The last equivalence comes from the relation

$$
\varphi_{i+1}^{F B}\left(\widehat{V}_{n-i-1}^{S B}+P\left(\widehat{V}_{n-i-1}^{S B}, M, T-t_{n-i-1}\right)\right)=\varphi_{i+1}^{S B}\left(\widehat{V}_{n-i-1}^{S B}\right)=0
$$

\section{Proof of Proposition 3}

(i) Simply remark that, from propositions 1 and 2 , if $r \leq \delta$ then $\mathcal{A}_{n-i}^{*}=\mathcal{E}_{n-i}=\Omega$ for all $1 \leq i \leq n-1$.

(ii) From lemma 1, corollary 1, propositions 1 and 2, we have

$$
\begin{aligned}
& \xi_{n}(0)=-\mathbb{E}\left[e^{-r t_{n}}\left(V\left(t_{n}\right)-S\left(t_{n}\right)\right) \mathbb{I}_{\left\{\mathcal{E}_{1} \cap \ldots \cap \mathcal{E}_{n}\right\}-\left\{\mathcal{A}_{1}^{*} \cap \ldots \cap \mathcal{A}_{n}^{*}\right\}}\right] \\
& +\sum_{i=1}^{n-1} \mathbb{E}\left[e^{-r t_{i}} \widetilde{S}\left(t_{i}\right) \mathbb{I}_{\left\{\mathcal{E}_{1} \cap \ldots \cap \mathcal{E}_{i}\right\}-\left\{\mathcal{A}_{1}^{*} \cap \ldots \cap \mathcal{A}_{i}^{*}\right\}}\right] .
\end{aligned}
$$

We want to prove $\xi_{n}(0)-\xi_{n-1}(0) \geq 0$.

Remark that

(i) $\left(\mathcal{E}_{1} \cap \ldots \cap \mathcal{E}_{n}\right)-\left(\mathcal{A}_{1}^{*} \cap \ldots \cap \mathcal{A}_{n}^{*}\right)=\Delta_{1} \cap \ldots \cap \Delta_{n}$ where $\Delta_{i} \stackrel{\text { def }}{=} \mathcal{E}_{i}-\mathcal{A}_{i}^{*} \quad \forall 1 \leq i \leq n$.

(ii) $\mathbb{1}_{\Delta_{1} \cap \ldots \cap \Delta_{i}}-\mathbb{I}_{\Delta_{2} \cap \ldots \cap \Delta_{i}}=-1 \quad \forall 2 \leq i \leq n$.

We deduce

$$
\begin{aligned}
\xi_{n}(0)-\xi_{n-1}(0)= & \mathbb{E}\left[e^{-r t_{n}}\left(V\left(t_{n}\right)-S\left(t_{n}\right)\right)\left(\mathbb{I}_{\Delta_{2} \cap \ldots \cap \Delta_{n}-\Delta_{1}}\right)\right] \\
& -\sum_{i=2}^{n-1} \mathbb{E}\left[e^{-r t_{i}} \widetilde{S}\left(t_{i}\right)\left(\mathbb{I}_{\Delta_{2} \cap \ldots \cap \Delta_{i}-\Delta_{1}}\right)\right]+\mathbb{E}\left[e^{-r t_{1}} \widetilde{S}\left(t_{1}\right) \mathbb{I}_{\Delta_{1}}\right] .
\end{aligned}
$$

Now, let us introduce the measure $Q^{V}$ (resp. $Q^{S}$ ) defined by its Radon-Nikodym derivative with respect to the measure $Q$ :

$$
\frac{d Q^{V}}{d Q}=\frac{V(T)}{\mathbb{E}^{Q}(V(T)]}
$$

(resp.

$$
\left.\frac{d Q^{S}}{d Q}=\frac{S(T)}{\mathbb{E}^{Q}(S(T)]}\right)
$$


A direct computation yields then :

$$
\begin{aligned}
\xi_{n}(0)-\xi_{n-1}(0) & =V_{0} \mathbb{E}^{Q^{V}}\left[\mathbb{I}_{\Delta_{2} \cap \ldots \cap \Delta_{n}-\Delta_{1}}\right] \\
& +S_{0} e^{-(r-\delta) t_{n}} \mathbb{E}^{Q^{S}}\left[\mathbb{I}_{\Delta_{2} \cap \ldots \cap \Delta_{n-1}-\Delta_{1}}-\mathbb{I}_{\Delta_{2} \cap \ldots \cap \Delta_{n}-\Delta_{1}}\right] \\
& +\sum_{i=2}^{n-2} S_{0} e^{-(r-\delta) t_{i+1}} \mathbb{E}^{Q^{S}}\left[\mathbb{I}_{\Delta_{2} \cap \ldots \cap \Delta_{i}-\Delta_{1}}-\mathbb{I}_{\Delta_{2} \cap \ldots \cap \Delta_{i+1}-\Delta_{1}}\right] \\
& +S_{0} e^{-(r-\delta) t_{1}} \mathbb{E}^{Q^{S}}\left[\mathbb{I}_{\Delta_{1}}\right]-S_{0} e^{-(r-\delta) t_{2}} \mathbb{E}^{Q^{S}}\left[\mathbb{I}_{\Delta_{1}}+\mathbb{I}_{\Delta_{2}-\Delta_{1}}\right] .
\end{aligned}
$$

To obtain the result, simply remark that:

(i) $\mathbb{I}_{\Delta_{2} \cap \ldots \cap \Delta_{i}-\Delta_{1}}-\mathbb{I}_{\Delta_{2} \cap \ldots \Delta_{i+1}-\Delta_{1}} \geq 0 \quad$ a.s $\quad \forall 2 \leq i \leq n-1$

(ii) $e^{-(r-\delta) t_{1}}>e^{-(r-\delta) t_{2}}$ and $\mathbb{E}^{Q^{S}}\left[\mathbb{I}_{\Delta_{1}}\right] \geq \mathbb{E}^{Q^{S}}\left[\mathbb{I}_{\Delta_{1}}+\mathbb{I}_{\Delta_{2}-\Delta_{1}}\right]=\mathbb{E}^{Q^{S}}\left[\mathbb{I}_{\Delta_{1} \cap \Delta_{2}}\right]$.

\section{Proof of Proposition 4}

Proof of part (i)

By backward induction on the scrapping dates $t_{n-i}$ we prove, for $i=0, n-1$, that renegotiation occurs at date $t_{n-i}$ iff the first best rule is not respected i.e:

$$
C_{i}\left(V\left(t_{n-i}\right), S\left(t_{n-i}\right), t_{n-i}\right) \leq \widetilde{S}\left(t_{n-i}\right)
$$

The proof is non technical and for seek of concision we only give the detail of the argumentation for the renegotiation game at date $t_{n-i-1}$.

Thus, let us assume date $t_{n-i-1}$ is reached. When deciding whether or not they should make a renegotiation offer, debtholders take into consideration the possibility that renegotiation could occur at date $t_{n-i}$, and so do equityholders when deciding upon accepting an offer. Three events may happens at date $t_{n-i}$ :

$\mathcal{A}_{n-i}=\left\{\right.$ equityholders decide to stop the firm at date date $t_{n-i}$ without renegotiation $\}$, $\mathcal{B}_{n-i}=\left\{\right.$ equityholders decide to stop the firm at date date $t_{n-i}$ following a renegotiation $\}$, 
$\mathcal{C}_{n-i}=\left\{\right.$ equityholders decide to continue the activity of the firm at date date $t_{n-i}$ without renegotiation $\}$.

More formally, using the induction assumption:

$$
\begin{aligned}
\mathcal{A}_{n-i}= & \left\{C_{i}\left(V\left(t_{n-i}\right)+P\left(V\left(t_{n-i}\right), M, T-t_{n-i}\right), S\left(t_{n-i}\right), t_{n-i}\right) \leq \widetilde{S}\left(t_{n-i}\right)\right\}, \\
\mathcal{B}_{n-i}= & \left\{C_{i}\left(V\left(t_{n-i}\right)+P\left(V\left(t_{n-i}\right), M, T-t_{n-i}\right), S\left(t_{n-i}\right), t_{n-i}\right) \geq \widetilde{S}\left(t_{n-i}\right)\right. \\
& \text { and } \left.C_{i}\left(V\left(t_{n-i}\right), S\left(t_{n-i}\right), t_{n-i}\right) \leq \widetilde{S}\left(t_{n-i}\right)\right\}, \\
\mathcal{C}_{n-i}= & \left\{C_{i}\left(V\left(t_{n-i}\right), S\left(t_{n-i}\right), t_{n-i}\right) \geq \widetilde{S}\left(t_{n-i}\right)\right\} .
\end{aligned}
$$

Suppose debtholders offer $R_{n-i-1}$ to the equityholders against immediate closure. Equityholders and debtholders compare their payoff under renegotiation and their payoff without renegotiation. Using lemma 4, a direct analysis shows that equityholders will accept the offer iff:

$$
\begin{aligned}
& \mathbb{E}_{t_{n-i-1}}\left[e ^ { - r ( t _ { n - i } - t _ { n - i - 1 } ) } \left(C_{i}\left(V\left(t_{n-i}\right)+P\left(V\left(t_{n-i}\right), M, T-t_{n-i}\right), S\left(t_{n-i}\right), t_{n-i}\right)\right.\right. \\
& \left.\left.+e^{-(r-\delta)\left(t_{n-i+1}-t_{n-i}\right)} S\left(t_{n-i}\right)-M e^{-r\left(T-t_{n-i}\right)}\right)\left(1-\mathbb{I}_{\mathcal{A}_{n-i}}\right)+\left(S\left(t_{n-i}\right)-M e^{-r\left(T-t_{n-i}\right)}\right) \mathbb{I}_{\mathcal{A}_{n-i}}\right] \\
& \leq \max \left\{S\left(t_{n-i-1}\right)-M e^{-r\left(T-t_{n-i-1}\right)}, 0\right\}+R_{n-i-1} .
\end{aligned}
$$

The best offer from the point of vue of the debtholders is of course the lowest $R_{n-i-1} \equiv$ $\underline{R}_{n-i-1}$ satisfying this equation. That is:

$$
\begin{aligned}
& \underline{R}_{n-i-1}=\mathbb{E}_{t_{n-i-1}}\left[e ^ { - r ( t _ { n - i } - t _ { n - i - 1 } ) } \left(C_{i}\left(V\left(t_{n-i}\right)+P\left(V\left(t_{n-i}\right), M, T-t_{n-i}\right), S\left(t_{n-i}\right), t_{n-i}\right)\right.\right. \\
& \left.\left.\left.+e^{-(r-\delta)\left(t_{n-i+1}-t_{n-i}\right)} S\left(t_{n-i}\right)-M e^{-r\left(T-t_{n-i}\right)}\right)\left(1-\mathbb{I}_{\mathcal{A}_{n-i}}\right)+\left(S\left(t_{n-i}\right)-M e^{-r\left(T-t_{n-i}\right)}\right) \mathbb{I}_{\mathcal{A}_{n-i}}\right)\right] \\
& -\max \left\{S\left(t_{n-i-1}\right)-M e^{-r\left(T-t_{n-i-1}\right)}, 0\right\} .
\end{aligned}
$$

Debtholders compare their payoff under renegotiation and their payoff without renegotiation. We deduce thus renegotiation happens iff:

$$
\begin{aligned}
& \min \left(S\left(t_{n-i-1}\right), M e^{-r\left(T-t_{n-i-1}\right)}\right)-\underline{R}_{n-i-1} \geq \mathbb{E}_{t_{n-i-1}}\left[e ^ { - r ( t _ { n - i } - t _ { n - i - 1 } ) } \left(M e^{-r\left(T-t_{n-i}\right)} \mathbb{I}_{\mathcal{A}_{n-i}}\right.\right. \\
& +\left(S\left(t_{n-i}\right)-C_{i}\left(V\left(t_{n-i}\right)+P\left(V\left(t_{n-i}\right), M, T-t_{n-i}\right), S\left(t_{n-i}\right), t_{n-i}\right)-e^{-(r-\delta)\left(t_{n-i+1}-t_{n-i}\right)} S\left(t_{n-i}\right)\right. \\
& \left.+M e^{-r\left(T-t_{n-i}\right)}\right) \mathbb{I}_{\mathcal{B}_{n-i}} \\
& +\left(C_{i}\left(V\left(t_{n-i}\right), S\left(t_{n-i}\right), t_{n-i}\right)-C_{i}\left(V\left(t_{n-i}\right)+P\left(V\left(t_{n-i}\right), M, T-t_{n-i}\right), S\left(t_{n-i}\right), t_{n-i}\right)\right. \\
& \left.\left.\left.-e^{-(r-\delta)\left(t_{n-i+1}-t_{n-i}\right)} S\left(t_{n-i}\right)+M e^{-r\left(T-t_{n-i}\right)}\right) \mathbb{I}_{\mathcal{C}_{n-i}}\right)\right] .
\end{aligned}
$$


Rearranging the terms of this last equation yields debtholders will renegotiate in the way describe above if and only if:

$$
\begin{aligned}
& S\left(t_{n-i-1}\right) \geq \mathbb{E}_{t_{n-i-1}}\left[e^{-r\left(t_{n-i}-t_{n-i-1}\right)}\left(C_{i}\left(V\left(t_{n-i}\right), S\left(t_{n-i}\right), t_{n-i}\right)-\widetilde{S}\left(t_{n-i}\right)\right) \mathbb{I}_{\mathcal{C}_{n-i}}+S\left(t_{n-i}\right)\right] \\
& \Longleftrightarrow \widetilde{S}\left(t_{n-i-1}\right) \geq C_{i-1}\left(V\left(t_{n-i-1}\right), S\left(t_{n-i-1}\right), t_{n-i-1}\right) .
\end{aligned}
$$

\section{Proof of part ii)}

We have to compare the expected payoff of the debtholders with what they would get in the absence of any agency conflict. In both cases, the operating policy is given by the first best rule, as shown in part (i). But, to induce the equityholders to choose the efficient decision, debtholders have to pay $\underline{R}_{n-i-1}$ when renegotiation occurs. Assume for instance, at date $t_{n-i}$ the event

$$
\begin{aligned}
& \left\{C_{i}\left(V\left(t_{n-i}\right)+P\left(V\left(t_{n-i}\right), M, T-t_{n-i}\right), S\left(t_{n-i}\right), t_{n-i}\right)>\tilde{S}\left(t_{n-i}\right)\right. \\
& \text { and } C_{i}\left(V\left(t_{n-i}, S\left(t_{n-i}\right), t_{n-i}\right)<\tilde{S}\left(t_{n-i}\right)\right\} .
\end{aligned}
$$

occurs $^{22}$ then the value of the debt at date $t_{n-i}$ in presence of agency conflicts and interim renegotiation is

$$
\begin{aligned}
& S\left(t_{n-i}\right)-C_{i}\left(V\left(t_{n-i}\right)+P\left(V\left(t_{n-i}, M, T-t_{n-i}\right), S\left(t_{n-i}\right), t_{n-i}\right)\right. \\
& -e^{-(r-\delta)\left(t_{n-i+1}-t_{n-i}\right)} S\left(t_{n-i}\right)+M e^{-r\left(t_{n}-t_{n-i}\right)} .
\end{aligned}
$$

In a world without agency conflicts, where a benevolent party would choose the operating decision maximizing the total value of the claims, the payoff of a zero coupon if the same event occurs would be $\min \left\{S\left(t_{n-i}\right), M e^{-r\left(T-t_{n-i}\right)}\right\}$. Using our lemma 3 and the put call parity formula it is easy to see that

$$
\begin{aligned}
& S\left(t_{n-i}\right)-C_{i}\left(V\left(t_{n-i}\right)+P\left(V\left(t_{n-i}, M, T-t_{n-i}\right), S\left(t_{n-i}\right), t_{n-i}\right)\right. \\
& -e^{-(r-\delta)\left(t_{n-i+1}-t_{n-i}\right)} S\left(t_{n-i}\right)+M e^{-r\left(t_{n}-t_{n-i}\right)}<\min \left\{S\left(t_{n-i}\right), M e^{-r\left(T-t_{n-i}\right)}\right\} .
\end{aligned}
$$

We can check in all other state of natures at date $t_{n-i}$, the expected payoffs of the debtholders are the same in both cases (the conflict case and the one with agency conflicts and interim renegotiation). Same arguments apply for other dates. This ends the proof.

\footnotetext{
${ }^{22}$ This event is exactly the event " equityholders want to continue and this decision is inefficient."
} 


$$
\begin{aligned}
\mathcal{B}= & \left\{C\left(V\left(t_{1}+\tau\right)+P\left(V\left(t_{1}+\tau\right), M_{2}, T-t_{1}-\tau\right), S\left(t_{1}+\tau\right), t_{2}-t_{1}-\tau\right) \geq\right. \\
& \left.M e^{-r\left(T-t_{1}-\tau\right)}-S\left(t_{1}+\tau\right) e^{-(r-\delta)\left(t_{2}-t_{1}-\tau\right)}\right\} .
\end{aligned}
$$

where

$$
C\left(V\left(t_{1}+\tau\right)+P\left(V\left(t_{1}+\tau\right), M_{2}, T-t_{1}-\tau\right), S\left(t_{1}+\tau\right), t_{2}-t_{1}-\tau\right)
$$

denotes the price at date $t_{1}+\tau$ of the option to exchange at date $t_{2} S\left(t_{2}\right)$ for $V\left(t_{2}\right)+$ $P\left(V\left(t_{2}\right), M_{2}, T-t_{2}\right)$.

We now turn to the derivation of the continuation set $\mathcal{E}_{1}^{\prime}$. Using risk neutral valuation we obtain:

$$
\begin{gathered}
\mathcal{E}_{1}^{\prime}=\left\{\mathbb { E } _ { t _ { 1 } } \left[e ^ { - r \tau } \left(\mathbb { E } _ { t _ { 1 } + \tau } \left[e^{-r\left(T-t_{1}-\tau\right)}\left(V(T)-M_{2}\right)^{+} \mathbb{I}_{\mathcal{E}_{2}^{\prime}}\right.\right.\right.\right. \\
\left.\left.\left.+e^{-r\left(t_{2}-t_{1}-\tau\right)}\left(S\left(t_{2}\right)-M_{2} e^{-r\left(T-t_{2}\right)}\right)^{+}\left(1-\mathbb{I}_{\mathcal{E}_{2}^{\prime}}\right)\right]-M_{1}\right) \mathbb{I}_{\mathcal{B}}\right] \\
\left.\geq S\left(t_{1}\right)-M e^{-r\left(T-t_{1}\right)}\right\} . \\
\mathcal{E}_{1}^{\prime}=\left\{\mathbb { E } _ { t _ { 1 } } \left[e ^ { - r \tau } \left(\mathbb{E}_{t_{1}+\tau}\left[e^{-r\left(t_{2}-t_{1}-\tau\right)}\left(C\left(V\left(t_{2}\right), M_{2}, T-t_{2}\right)-S\left(t_{2}\right)+M_{2} e^{-r\left(T-t_{2}\right)}\right) \mathbb{I}_{\mathcal{E}_{2}^{\prime}}\right]\right.\right.\right. \\
\left.\left.\left.\quad-M_{1}-M_{2} e^{-r\left(T-t_{1}-\tau\right)}+S\left(t_{2}\right) e^{-r\left(t_{2}-t_{1}-\tau\right)}\right) \mathbb{I}_{\mathcal{B}}\right] \geq S\left(t_{1}\right)-M e^{-r\left(T-t_{1}\right)}\right\} . \\
\mathcal{E}_{1}^{\prime}=\quad\left\{\mathbb { E } _ { t _ { 1 } } \left[e ^ { - r \tau } \left(\mathbb{E}_{t_{1}+\tau}\left[e^{-r\left(t_{2}-t_{1}-\tau\right)}\left(P\left(V\left(t_{2}\right), M_{2}, T-t_{2}\right)+V\left(t_{2}\right)-S\left(t_{2}\right)\right) \mathbb{I}_{\mathcal{E}_{2}^{\prime}}\right]\right.\right.\right. \\
\mathcal{E}_{1}^{\prime}=\left\{\mathbb { E } _ { t _ { 1 } } \left[e ^ { - r \tau } \left(C\left(V\left(t_{1}+\tau\right)+P\left(V\left(t_{1}+\tau\right), M_{2}, T-t_{1}-\tau\right), S\left(t_{1}+\tau\right), t_{2}-t_{1}-\tau\right)\right.\right.\right. \\
\left.\left.\left.\quad M e^{-r\left(T-t_{1}-\tau\right)}+S\left(t_{2}\right) e^{-r\left(t_{2}-t_{1}-\tau\right)}\right)^{+}\right] \geq S\left(t_{1}\right)-M e^{-r\left(T-t_{1}\right)}\right\} .
\end{gathered}
$$

where

$$
C\left(V\left(t_{1}+\tau\right)+P\left(V\left(t_{1}+\tau\right), M_{2}, T-t_{1}-\tau\right), S\left(t_{1}+\tau\right), t_{2}-t_{1}-\tau\right)
$$

denotes the price at date $t_{1}+\tau$ of the option to exchange at date $t_{2}, S\left(t_{2}\right)$ for $V\left(t_{2}\right)+$ $P\left(V\left(t_{2}\right), M_{2}, T-t_{2}\right)$.

Now remark that, as the total indebtness $M$ is held constant, the event $\mathcal{E}_{1}^{\prime}$ only depends on $M_{1} \in\left[0, M e^{-r\left(T-t_{1}-\tau\right)}\right]$ through the relation $M_{2}=M-M_{1} e^{r\left(T-t_{1}-\tau\right)}$. Comparative 
statics results give then the decreasness of the continuation decision set $\mathcal{E}_{1}^{\prime}$ in $M_{1}$. Moreover, for $M_{1}=0$, one gets from lemma 3 and the put-call parity formula:

$$
\begin{aligned}
& \left(C\left(V\left(t_{1}+\tau\right)+P\left(V\left(t_{1}+\tau\right), M, T-t_{1}-\tau\right), S\left(t_{1}+\tau\right), t_{2}-t_{1}-\tau\right)-M e^{-r\left(T-t_{1}-\tau\right)}+S\left(t_{2}\right) e^{-r\left(t_{2}-t_{1}-\tau\right)}\right)^{+} \\
& =\left(C\left(V\left(t_{1}+\tau\right)+P\left(V\left(t_{1}+\tau\right), M, T-t_{1}-\tau\right), S\left(t_{1}+\tau\right), t_{2}-t_{1}-\tau\right)-M e^{-r\left(T-t_{1}-\tau\right)}+S\left(t_{2}\right) e^{-r\left(t_{2}-t_{1}-\tau\right)}\right)
\end{aligned}
$$

We then obtain:

$$
\mathcal{E}_{1}^{\prime}=\left\{C_{1}\left(V\left(t_{1}\right)+P\left(V\left(t_{1}\right), M, T-t_{1}\right), S\left(t_{1}\right), t_{1}\right) \geq \tilde{S}\left(t_{1}\right)\right\}=\mathcal{E}_{1} .
$$

On the other hand, for $M_{1}=M e^{-r\left(T-t_{1}\right)}$, we have $M_{2}=0$ and thus $P\left(V\left(t_{1}\right), M_{2}, T-t_{1}\right)=$ 0 which leads to

$$
\mathcal{A}_{1}^{*}=\left\{C_{1}\left(V\left(t_{1}\right), S\left(t_{1}\right), t_{1}\right) \geq \tilde{S}\left(t_{1}\right)\right\} \subset \mathcal{E}_{1}^{\prime} .
$$

To see this last inclusion remark that:

$$
\begin{aligned}
\mathcal{A}_{1}^{*}= & \left\{C_{1}\left(V\left(t_{1}\right), S\left(t_{1}\right), t_{1}\right) \geq \tilde{S}\left(t_{1}\right)\right\} \\
= & \left\{C_{1}\left(V\left(t_{1}\right), S\left(t_{1}\right), t_{1}\right)-M e^{-r\left(T-t_{1}\right)}+S\left(t_{1}\right) e^{-(r-\delta)\left(t_{2}-t_{1}\right)} \geq S\left(t_{1}\right)-M e^{-r\left(T-t_{1}\right)}\right\} \\
= & \left\{\mathbb{E}_{t_{1}}\left[e^{-r \tau}\left(C\left(V\left(t_{1}+\tau\right), S\left(t_{1}+\tau\right), t_{2}-t_{1}-\tau\right)-M e^{-r\left(T-t_{1}-\tau\right)}+S\left(t_{2}\right) e^{-r\left(t_{2}-t_{1}-\tau\right)}\right)\right]\right. \\
& \left.\geq S\left(t_{1}\right)-M e^{-r\left(T-t_{1}\right)}\right\} \\
\subset & \left\{\mathbb{E}_{t_{1}}\left[e^{-r \tau}\left(C\left(V\left(t_{1}+\tau\right), S\left(t_{1}+\tau\right), t_{2}-t_{1}-\tau\right)-M e^{-r\left(T-t_{1}-\tau\right)}+S\left(t_{2}\right) e^{-r\left(t_{2}-t_{1}-\tau\right)}\right)^{+}\right]\right. \\
& \left.\geq S\left(t_{1}\right)-M e^{-r\left(T-t_{1}\right)}\right\} .
\end{aligned}
$$

Assertion (ii) is thus proved.

Following the notations of proposition 2 , let define $w_{2}\left(V(0), S(0), 0 ; \mathcal{E}_{1}^{\prime}, \mathcal{E}_{2}^{\prime}, \mathcal{B}\right)$, the firm value at date 0 associated to the capital structure described in section 4.2. Let us denote by $\mathcal{B}^{c}$ the event "the firm is in bankruptcy at date $t_{1}+\tau$ ". A direct calculus shows

\section{Lemma 7 The following holds}

(i)

$$
\begin{aligned}
& w_{2}\left(V(0), S(0), 0 ; \mathcal{E}_{1}^{\prime}, \mathcal{E}_{2}^{\prime}, \mathcal{B}\right) \\
& \quad=\Phi_{2}\left(V(0), S(0), 0 ; \mathcal{E}_{1}^{\prime}, \mathcal{E}_{2}^{\prime}\right)-\mathbb{E}\left[e^{-r t_{2}}\left(V\left(t_{2}\right)-S\left(t_{2}\right)\right) \mathbb{1}_{\mathcal{E}_{1}^{\prime}} \mathbb{I}_{\mathcal{B}^{c}} \mathbb{1}_{\mathcal{E}_{2}^{\prime}-\mathcal{A}_{2}^{*}}\right] \\
& \quad=\Phi_{2}\left(V(0), S(0), 0 ; \mathcal{E}_{1}^{\prime}, \mathcal{A}_{2}^{*}\right)+\mathbb{E}\left[e^{-r t_{2}}\left(V\left(t_{2}\right)-S\left(t_{2}\right)\right) \mathbb{1}_{\mathcal{E}_{1}^{\prime}}\left(1-\mathbb{1}_{\mathcal{B}^{c}}\right) \mathbb{1}_{\mathcal{E}_{2}^{\prime}-\mathcal{A}_{2}^{*}}\right] .
\end{aligned}
$$


(ii) Let consider two sets $\overline{\mathcal{B}}$ and $\underline{\mathcal{B}}$ in $\mathcal{F}_{t_{1}+\tau}$ satisfying $\underline{\mathcal{B}} \subset \overline{\mathcal{B}}$ then:

$$
w_{2}\left(V(0), S(0), 0 ; \mathcal{E}_{1}^{\prime}, \mathcal{E}_{2}^{\prime}, \overline{\mathcal{B}}\right) \leq w_{2}\left(V(0), S(0), 0 ; \mathcal{E}_{1}^{\prime}, \mathcal{E}_{2}^{\prime}, \underline{\mathcal{B}}\right)
$$

We are now in a position to conclude the proof of proposition 5: Let $\underline{M}_{1}, \bar{M}_{1}$ two coupons satisfying $0 \leq \underline{M}_{1}<\bar{M}_{1} \leq M e^{-r\left(T-t_{1}-\tau\right)}$. Let denote $\mathcal{E}_{1}^{\prime}\left(\underline{M}_{1}\right), \mathcal{E}_{2}^{\prime}\left(\underline{M}_{1}\right), \mathcal{B}\left(\underline{M}_{1}\right)$ (resp: $\left.\mathcal{E}_{1}^{\prime}\left(\bar{M}_{1}\right), \mathcal{E}_{2}^{\prime}\left(\bar{M}_{1}\right), \mathcal{B}\left(\bar{M}_{1}\right)\right)$ the "continuation sets" and the "no bankruptcy set" associated to the capital structure described in section 4.2 where $\underline{M}_{1}$ has to be paid at date $t_{1}+\tau$ and $M-\underline{M}_{1} e^{r\left(T-t_{1}-\tau\right)}$ has to be paid at date $T$ (resp: where $\bar{M}_{1}$ has to be paid at date $t_{1}+\tau$ and $M-\bar{M}_{1} e^{r\left(T-t_{1}-\tau\right)}$ has to be paid at date $\left.T\right)$. Clearly from lemma 6 we have:

(i) $\mathcal{A}_{1}^{*} \subset \mathcal{E}_{1}^{\prime}\left(\bar{M}_{1}\right) \subset \mathcal{E}_{1}^{\prime}\left(\underline{M}_{1}\right) \subset \mathcal{E}_{1}$.

(ii) $\mathcal{A}_{2}^{*} \subset \mathcal{E}_{2}^{\prime}\left(\bar{M}_{1}\right) \subset \mathcal{E}_{2}^{\prime}\left(\underline{M}_{1}\right) \subset \mathcal{E}_{2}$.

(iii) $\mathcal{B}\left(\bar{M}_{1}\right) \subset \mathcal{B}\left(\underline{M}_{1}\right)$.

We then deduce

$$
\begin{aligned}
& w_{2}\left(V(0), S(0), 0 ; \mathcal{E}_{1}^{\prime}\left(\bar{M}_{1}\right), \mathcal{E}_{2}^{\prime}\left(\bar{M}_{1}\right), \mathcal{B}\left(\bar{M}_{1}\right)\right)-w_{2}\left(V(0), S(0), 0 ; \mathcal{E}_{1}^{\prime}\left(\underline{M}_{1}\right), \mathcal{E}_{2}^{\prime}\left(\underline{M}_{1}\right), \mathcal{B}\left(\underline{M}_{1}\right)\right) \\
& \geq w_{2}\left(V(0), S(0), 0 ; \mathcal{E}_{1}^{\prime}\left(\bar{M}_{1}\right), \mathcal{E}_{2}^{\prime}\left(\bar{M}_{1}\right), \mathcal{B}\left(\underline{M}_{1}\right)\right)-w_{2}\left(V(0), S(0), 0 ; \mathcal{E}_{1}^{\prime}\left(\underline{M}_{1}\right), \mathcal{E}_{2}^{\prime}\left(\underline{M}_{1}\right), \mathcal{B}\left(\underline{M}_{1}\right)\right) \\
& =\mathbb{E}\left[e^{-r t_{2}}\left(V\left(t_{2}\right)-S\left(t_{2}\right)\right)\left(1-\mathbb{I}_{\mathcal{B}^{c}\left(\underline{M}_{1}\right)}\right)\left(\mathbb{I}_{\mathcal{E}_{1}^{\prime}\left(\bar{M}_{1}\right)} \mathbb{I}_{\mathcal{E}_{2}^{\prime}\left(\bar{M}_{1}\right)-\mathcal{A}_{2}^{*}}-\mathbb{I}_{\mathcal{E}_{2}^{\prime}\left(\underline{M}_{1}\right)} \mathbb{I}_{\mathcal{E}_{2}^{\prime}\left(\underline{M}_{1}\right)-\mathcal{A}_{2}^{*}}\right)\right] \\
& +\Phi_{2}\left(V(0), S(0), 0 ; \mathcal{E}_{1}^{\prime}\left(\bar{M}_{1}\right), \mathcal{A}_{2}^{*}\right)-\Phi_{2}\left(V(0), S(0), 0 ; \mathcal{E}_{1}^{\prime}\left(\underline{M}_{1}\right), \mathcal{A}_{2}^{*}\right) \geq 0 \text {. }
\end{aligned}
$$

Where the first inequality comes from part (ii) of lemma 7. Part (i) of lemma 7 gives the equality. For the last inequality, simply remark that the relations $\mathcal{E}_{1}^{\prime}\left(\bar{M}_{1}\right) \subset \mathcal{E}_{1}^{\prime}\left(\underline{M}_{1}\right)$ and $\mathcal{A}_{2}^{*} \subset \mathcal{E}_{2}^{\prime}\left(\bar{M}_{1}\right) \subset \mathcal{E}_{2}^{\prime}\left(\underline{M}_{1}\right)$ imply

$$
\mathbb{E}\left[e^{-r t_{2}}\left(V\left(t_{2}\right)-S\left(t_{2}\right)\right)\left(1-\mathbb{I}_{\mathcal{B}^{c}\left(\underline{M}_{1}\right)}\right)\left(\mathbb{I}_{\mathcal{E}_{1}^{\prime}\left(\bar{M}_{1}\right)} \mathbb{I}_{\mathcal{E}_{2}^{\prime}\left(\bar{M}_{1}\right)-\mathcal{A}_{2}^{*}}-\mathbb{I}_{\mathcal{E}_{2}^{\prime}\left(\underline{M}_{1}\right)} \mathbb{I}_{\mathcal{E}_{2}^{\prime}\left(\underline{M}_{1}\right)-\mathcal{A}_{2}^{*}}\right)\right] \geq 0
$$

and that, from lemma 5, the difference

$$
\Phi_{2}\left(V(0), S(0), 0 ; \mathcal{E}_{1}^{\prime}\left(\bar{M}_{1}\right), \mathcal{A}_{2}^{*}\right)-\Phi_{2}\left(V(0), S(0), 0 ; \mathcal{E}_{1}^{\prime}\left(\underline{M}_{1}\right), \mathcal{A}_{2}^{*}\right)
$$

is also positive. The proof of proposition 5 is complete. 


\section{References}

Anderson, R. and S. Sundaresan, 1996, "Design and Valuation of Debt Contracts." Review of Financial Studies 9, 37-68.

Carr, P. 1988, "The Valuation of Sequential Exchange Opportunities," Journal of Finance, $5,1235-56$.

Décamps, J.P. and J.C. Rochet, 1997, "A Variational Approach for Pricing Options and Corporate Bonds." Economic Theory, 9, 557-569.

Dewatripont, M. et J. Tirole, 1994, "A Theory if Debt and Equity: Diversity of Securities and Manager-Shareholder Congruence." Quarterly Journal of Economics, 439, 1027-1054.

Dixit, A.K and R.S Pyndick, 1994, "Investment under Uncertainty", Princeton University Press, Princeton.

Ericsson, J., 1997, "Asset Substitution, Debt Pricing, Optimal Leverage and Maturity", WP Stockholm School of Economics.

Ericsson, J. and J. Reneby, 1997, "Implementing Firm Value Based Models", Working Paper, Stockholm School of Economics.

Gerber, H.U. and E.S. Shiu 1996, "Martingale Approach To Pricing Perpetual American Options on Two Stocks." Mathematical Finance, 3, 303-22.

Geske, R. 1977, "The Valuation of Corporate Liabilities as Compound Options." Journal of Financial and Quantitative Analysis, 12,541-52

Geske, R. and H. Johnson 1984, "The American Put Option Valued Analitycally," Journal of Finance, 39, 1511-24.

Grinblatt, M. and S. Titman, 1998, Financial Markets and Corporate Strategy, Irwin/McGrawwHill. 
Harris, M. and A. Raviv, 1991, "The Theory of Capital Structure." The Journal of Finance, 46, 297-355.

Harrison, M. and D. Kreps, 1979, "Martingales and Arbitrage in Multiperiod Securities Markets", Journal of Economic Theory, 20, 381-408.

Hart, O. and J. Moore, 1989, "Default and Renegotiation: a Dynamic Model of Debt." Mit Working Paper.

Hart, O. and J. Moore, 1994, "A Theory of Debt Based on the Inalienability of Human Capital." Quaterly Journal of Economics, 109, 841-79.

Hart, O. and J. Moore, 1996, "Debt, Default and Renegotiation." Mimeo Harvard University, 46, 297-355.

Jensen M. et W. Meckling, 1976, "Theory of the Firm: Managerial Behavior, Agency Costs and Ownership Structure.” Journal of Financial Economics, October, 305-360.

Leland, H., 1994, "Risky Debt, Bond Covenants and Optimal Capital Structure." Journal of Finance, 49, 1213-1252.

Leland, H., 1998, "Agency Costs, Risk Management, and Capital Structure," Journal of Finance, 4, 1213-43.

Leland, H. and K. Toft, 1996, "Optimal Capital Structure, Endogenous Bankruptcy, and the Term Structure of Credit Spread." Journal of Finance, 51, 987-1019.

Margrabe W., 1978, "The Value of an Option to Exchange One Asset for Another." Journal of Finance, 33, 177-186.

Mauer, D.C and S.H Ott, 1998, "Agency Costs, Underinvestment, and Optimal Capital Structure: The Effect of Growth Options to Expand," Forthcoming in M.J Brennan and L. Trigeorgis (eds), "Innovation, Infrastructure and Strategic Options," London: Oxford University Press. 
McDonald R., and D.R. Siegel 1985, "Investment and Valuation of Firms When There is An Option To Shut Down," International Economic Review, 26, 2, 331-49.

Mella-Barral P., 1999, "The Dynamics of Default and Debt Reorganization." Review of Financial Studies, 12, 3, 535-79.

Mella-Barral P. and W. Perraudin, 1997, "Strategic Debt Service." Journal of Finance, 2, 531-556.

Mello, A. and J. Parsons, 1992, "Measuring Agency Cost of Debt." Journal of Finance, 4, 141-183.

Merton, R., 1974, "On the pricing of Corporate Debt: The Risk Structure of Interest Rates." Journal of Finance, 29, 449-469.

Myers, S., 1977, "Determinants of Corporate Borrowing". Journal of Financial Economics, 5, 147-175.

Parrino, R. and M, Weisbach 1999, "Measuring Investment Distortions Arising from Stockholders-Bondholders Conflicts." Journal of Financial Analysis, 53, 1, 3-42.

Sick, G. 1995, "Real Options," Handbooks in Operations Research and Management Science, Vol 9, Finance, Editors: R.A. Jarrow, V. Maksimovic and W.T. Ziemba. 